\title{
On the Varieties of Conscious Experiences: Altered Beliefs Under Psychedelics (ALBUS)
}

\author{
Adam Safron ${ }^{1,2,3,4^{*}}$ \\ ${ }^{1}$ Center for Psychedelic and Consciousness Research, Department of Psychiatry \& Behavioral Sciences, \\ Johns Hopkins University School of Medicine, Baltimore, MD, USA \\ ${ }^{2}$ Institute for Advanced Consciousness Studies, Santa Monica, CA, USA \\ ${ }^{3}$ Kinsey Institute, Indiana University, Bloomington, IN, USA \\ ${ }^{4}$ Cognitive Science Program, Indiana University, Bloomington, IN, USA \\ *asafron@gmail.com

\section{Abstract}

How is it that psychedelics so profoundly impact brain and mind? According to the highly

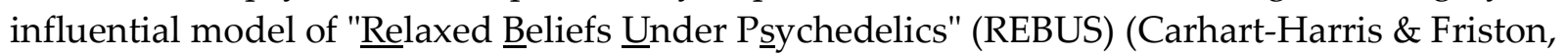
2019), 5-HT2a agonism is thought to help relax prior expectations, so making room for new perspectives and patterns. This model is contextualized within the Free Energy Principle and Active Inference framework, as well as the associated neuronal processes theory of hierarchical predictive processing. More specifically, excessive excitation of deep pyramidal neurons is thought to cause paradoxical desynchronization, so "flattening" (Bayesian) "belief landscapes" by attenuating large-scale complexes of synchronous neural activity. Inspired by the REBUS model, here we introduce an alternative (but largely compatible) perspective, in that while such effects may be both real and important, these alterations may primarily correspond to a rare (but potentially pivotal) regime of very high levels of serotonin 2a receptor (5-HT2aR) agonism. We suggest an opposite effect may occur along much of the dose-response curve of 5-HT2aR stimulation, in which synchronous neural activity becomes more powerful, with accompanying

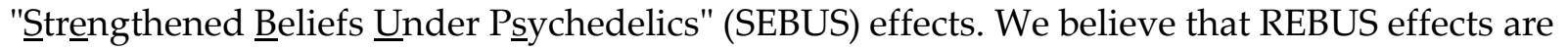
indeed crucially important aspects of psychedelic experiences, but suggest these exist alongside SEBUS effects in various combinations. As such, we propose a larger integrative perspective for

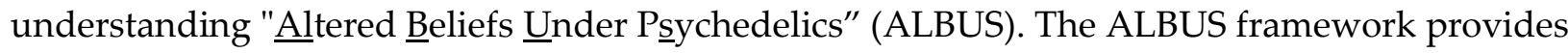
a rich account of cognition based on predictive processing, which we believe provides a means of fruitfully integrating across theories of psychedelic action ranging from REBUS, to "thalamic gating" (Preller et al., 2019), to the newly suggested "cortico-striatal thalamo-cortical" model (Doss et al., 2021). Towards this end we demonstrate the utility of ALBUS by providing neurophenomenological models of psychedelics focusing on mechanisms of conscious perceptual synthesis, as well as hippocampally-orchestrated episodic memory and mental simulation. We further discuss cognitive diversity (including psychopathology) through the lens of these models. We consider the potential significances of modifications of the default mode network and alpha rhythms for creativity and various states of consciousness, including with respect to fundamental alterations in sense of self through ego dissolution. Finally, we 
survey a broad range of psychedelic phenomena and consider potential explanations, implications, and directions for future work.

\section{Contents}

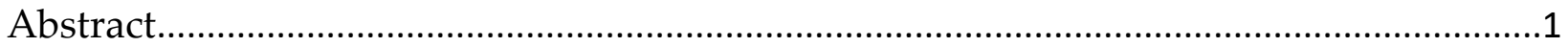

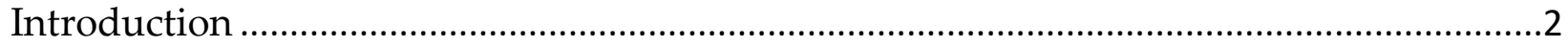

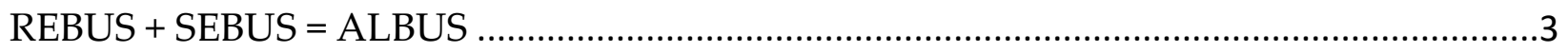

Neurophenomenological models of psychedelics .......................................................

ALBUS and Complex Causation: SEBUS via REBUS; REBUS via SEBUS ...................... 21

Which beliefs are we altering under what circumstances? ........................................... 25

Psychedelics, psychopathology, and cognitive spectrums .......................................... 31

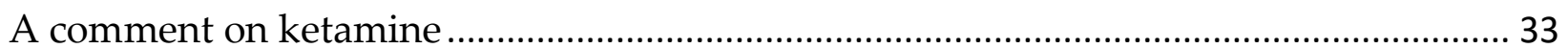

Breaking free of (and via) default modes; creativity and consciousness ........................ 33

Alpha rhythms, ego dissolution, and varieties of conscious experiences ....................... 36

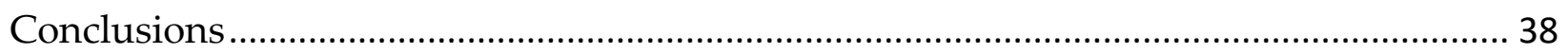

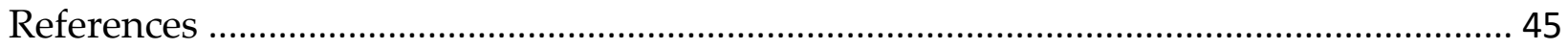

\section{Introduction}

The evolving "psychedelic renaissance" has the potential to alter society in countless ways (Pollan, 2018, 2021). Psychedelics have been shown to cause relatively reliable life-altering personal transformations that are almost unheard of in the clinical sciences (Johnson et al., 2019). At the same time, efforts to decriminalize and legalize psychedelics at the local and state levels in the US have seen initial success. In light of these potentially radical changes, it is essential that we have detailed and accurate models of these powerful compounds for this psychedelic revolution to avoid undesirable outcomes and live up to its promise. In what follows, we attempt to bring together different aspects of major theories to create a "minimum unifying model" (Wiese, 2020), wherein insights from these diverse perspectives may be integrated (and where differences may potentially be adjudicated). We will show how these different perspectives on psychedelic action may be synergistically combined to create a whole that is greater than the sum of its parts. We will also explore how such understandings may illuminate fundamental scientific questions regarding mechanisms of mind, human nature, and potentially even selfhood and consciousness in all their various manifestations. 
Before beginning, we would like to acknowledge that this may be a challenging manuscript for many to read, both in terms of its length and level of detail. One could argue that this material could be broken up into a larger number of smaller manuscripts, but we believe this would be a mistake. Rather, we should expect complexity in trying to obtain sufficient understanding for doing meaningful (and reliable) basic and clinical science around psychedelics. Further, we believe such complexity cannot be sidestepped, in that not only would we be depriving ourselves of the opportunity to leverage converging lines of evidence as constraints on model development, but we also would have neglected trying to understand the very phenomena that we seek to modify: the experiences and hopefully intelligent goaloriented behavior of conscious beings. Towards this end, we have attempted to provide clarifying examples (and illustrations) to illustrate particularly challenging concepts. However, we also recognize that different content will be of different interest (and accessibility) to different individuals. This is not a problem, and interested readers can feel secure if all they take from a given section is the general principles underlying a worked example, rather than having a firm grasp on every technical detail. With these intentions in mind, we will now review the forerunners of the present proposal, introduce a set of mechanistic hypotheses for explaining core aspects of psychedelics, and then go on to explore implications and future directions for psychedelic research.

\section{REBUS + SEBUS $=$ ALBUS}

In introducing "eelaxed Beliefs $\underline{\text { Under P}}$ sychedelics" (REBUS), Carhart-Harris and Friston (2019) have presented a compelling account of the effects of psychedelics on brain and mind. This model is contextualized within the Free Energy Principle and Active Inference (FEP-AI) framework (Friston, 2010; Friston et al., 2006, 2017), which aims to provide a unified paradigm for the mind and life sciences. According to FEP-AI, mental systems adaptively regulate their actions and interactions with the world via predictive models, whose dynamics are governed by a singular objective of minimizing "free energy." In this view, minds (as kinds of models) are modeled as exhaustively constituted by ecosystems of statistical expectations (realized by networks of effective connectivity) that interact within heterarchical (i.e., multiple intersecting hierarchies) webs of 'beliefs' (which may or may not be consciously experienced). Informational free energy provides a means of evaluating models in terms of their accuracy (or ability to minimize prediction errors) and parsimony (or ability to fit data with minimal complexity). The free-energy (minimization) principle (FEP) so encapsulates the ideal of scientific hypothesis testing in which we seek maximally simple (but not simpler) explanations for data. Active inference (AI) extends this principle, prescribing what an agent should do if it is to successfully minimize free energy over time. Taken together, 
FEP-AI provides a framework for describing what we ought to expect from all intelligent systems, including human beings.

To provide a concrete example (which we will elaborate below), we may think of a person walking in nature. Under FEP-AI, this agent will both implicitly and explicitly 'predict' itself in desirable states where it may expect continuation of the preconditions for its existence. More specifically, under normal (and normative) conditions, we might expect a being like us to be predicting itself in states where it is healthy, happy, and living with ease. As an active inference agent encounters information that goes against these prior (to experience) expectations, two fundamental moves are available: updating internal working models (i.e., perceptual inference on shorter time scales; learning on longer time scales) or updating of world states to better match priors (i.e., active inference). Such a being will then engage in whatever combination of updating of internal models and world states most efficiently reduce overall prediction-error, with updating dynamics particularly influenced by the degree to which different information streams are biased via various forms of attention (computationally understood as degrees of "precision-weighting" over different probability distributions). For example, violation of predictions regarding adequate nutrient intake might result in hunger, which could then be resolved either by changing expectations (e.g., distracting oneself with other thoughts, or obtaining partial satisfaction via imaginative fulfillment of desires) or by changing world states (e.g. reaching out for an apple and eating it). With respect to attentional selection, if our agent is particularly hungry, it might be more likely to attend to apple-related sensations (e.g. focusing on apples within the visual field), so causing them to have more powerful influences on updating beliefs, and potentially the world. Intriguingly, this attending is also directly relevant to how goaloriented behavior is realized in FEP-AI, in terms of more strongly (and perhaps vividly) predicted (or attended to) imagined outcomes being more likely to exert control energy in governing behavior (Safron, 2021a).

Hierarchical predictive processing (HPP) provides a computational description of how free energy may be minimized by biological (and artificial) systems (Bastos et al., 2012). In brief (Figure 1), HPP views neural processes as generatively modeling the world, with predictions communicated top-down towards primary modalities to suppress bottom-up inputs from the senses, with unexpected observations passed upwards as prediction errors. These models are "generative" in that they create (or generate) likely patterns of sense-data, given past experience. This setup has information flowing in opposite directions to what might be expected, in that perception corresponds to the brain's internally-generated predictions, rather than constituting a faithful readout of incoming sense data. In light of how these models fundamentally depend on the creative synthesis of information from within, they have been described as characterizing subjective experience as a kind of "controlled hallucination" (Frith, 2005). 
Information from the eyes is highly distorted, with visual acuity of only a few degrees-approximately corresponding to a thumbnail held out at arm's length - and is further compromised by a large blindspot within each retina. Yet, we are capable of generating the impression of a far richer visual experience, suggesting that at least some degree of filling-in takes place to augment this noisy and ambiguous data. In HPP, perception is understood as a best-guess inference regarding the causes of sensory observations, where neural dynamics generate likely patterns of sense-data, given past learning. In this way, each moment of experience corresponds to a top-down prediction regarding bottom-up observations, which are updated whenever there are discrepancies with these prior expectations. Computationally, these predictions are understood as the "inversion" of generative models, with particular details being generated in a manner akin to those used to generate "deep fake" visual and auditory stimuli. While there are many technical details involved in inverting generative models, the basic idea is that when we have networks of connections that have been formed (or trained) based on information from the world, we can also use those patterns of connectivity to infer (or fill-in) likely patterns of sense data. Such machine learning architectures are becoming increasingly widely used in applications ranging from upscaling lower definition-television signals to higher resolutions, to creating virtual avatars of individuals based on their characteristic (or specifically modified) patterns in appearance and speech, to creating (or 'imagining') highly detailed and realistic simulations of individuals and worlds with features that are nearly completely novel. However, with respect to sources of phenomenal consciousness in the brain (Figure 2), neural dynamics would generate likely patterns of data for the entire sensorium as a kind of fully-immersive virtual reality. That is, from this view inspired by machine learning, we may understand the stream of consciousness as the iterative estimation of likely sensory states, inferred according to a coherent model of the world (Safron, 2020a, 2021b).

While many specific details are debated, theoretical efficiency and growing empirical support suggests HPP as an increasingly plausible interpretation of the common layered-columnar organization observed throughout cortex (Ahmad \& Scheinkman, 2019; Edelman \& Mountcastle, 1978; Hawkins \& Blakeslee, 2004; Mountcastle, 1997; Walsh et al., 2020). Perhaps even more suggestive of biological plausibility, "predictive coding" is efficient in that information only needs to be passed up the cortical hierarchy when expectations are violated. If such expectancies are largely accurate, and if events in the world evolve relatively slowly compared to neural signaling, then energetic savings could be substantial. For these, as well as other reasons (Ahmad \& Scheinkman, 2019), a surprisingly large amount of cognition may be explained in terms of hierarchical inference (Safron, 2020a, 2021b). However, with relevance to later discussions, it should be noted that HPP goes beyond predictive coding in also involving attention as a means of increasing the gain on particular beliefs 
(rather top-down influences all being of a strictly suppressive variety), so causing different sources of information to be more or less likely to contribute to integrated system-world modeling. In this way, a full account of belief dynamics within FEP-AI will require understanding not only how predictive coding may be modified by psychedelics, but also various mechanisms contributing to attentional selection.

With respect to our agent immersed in nature, we might naively expect the perception of something like an apple to correspond to a faithful readout of the information that's sufficiently determined by available sense data. Yet from an HPP perspective, we would instead understand perceived apples as corresponding to kinds of 'predictions' about what is expected to exist in the world, given sensory observations. While these two accounts may seem equivalent, in reality they can vary wildly, as demonstrated by visual illusions that show how we actually perceive what we expect. Concretely, a hungry agent may not just be more likely to be able to identify apples in a visual field, but it will actually attend to (and perceive) different aspects of apples in more or less detail based on its present context (e.g. its setting) and history of experiences with apples (e.g. its set). That is, hunger may cause apple-related percepts to appear in experience in ways that may be more vivid and/or richly detailed.

Similarly, we will suggest that psychedelics can have similar effects on experience by increasing "consciousness level" (i.e., the overall amount of signaling contributing to conscious states in any given 'moment') and/or potentially expanding the perceptual field in ways that allow for greater richness in terms of the amount and diversity of conscious contents held in mind.

Below we describe how low-level perceptual synthesis (Figures 1 and 2), conscious perception (Figures 2 and 3), and higher-order cognition (Figure 4) involve qualitatively different belief dynamics. These distinctions may be crucial for understanding the mechanistic and experiential bases of psychedelics, including the ways they alter what is likely to manifest in minds with various sets and settings. While HPP may provide a powerful unifying principle for understanding brain and mind, it is important not to conflate hierarchical cortical inference with cognition more generally. Nearly all biophysical processes may be described as engaging in predictive processing on some level of abstraction, but this does not mean that we can adequately account for all cognitive phenomena in terms of hierarchical Bayesian inference on the level of cortical microcircuitry. Such modeling of mind would be mistaken even if all cognition ultimately emerged from a single homogeneous algorithm. This reasoning would represent a "fallacy of composition," failing to account for how novel emergent properties can emerge as systems scale; or in other words, "more is different" (Anderson, 1972). This kind of overly simple account would be even more questionable in light of what we know about the fact that brains are complex organs with heterogenous subsystems that have been differentially shaped by natural selection. Nonetheless, if a common algorithm governs all cortical functioning, then we may be 
able to explain a surprising amount of cognition in terms of HPP, perhaps including with respect to psychedelic phenomenology.

According to REBUS, psychedelics alter HPP mechanisms in ways that flatten free energy landscapes, or the differential attracting forces associated with various (Bayesian) beliefs, so promoting flexibility in inference and learning. Algorithmically speaking, this would correspond to reduced "precision-weighting" over top-down prior expectations - functionally understood as reduced filtering of perception via attentional selection (Parr \& Friston, 2017) - so allowing bottom-up prediction errors to have a greater influence on inference and learning. Such relaxations of beliefs and enhanced capacity for updating may help explain why psychedelics appear to have transdiagnostic relevance across a broad range of conditions, which may be expected in light of the fact that flexibility is almost synonymous with an essential capacity for all complex adaptive systems: open-ended evolution (Atasoy et al., 2019; Brouwer \& Carhart-Harris, 2020; Hayes, 2019; Hinton \& Kirmayer, 2017; Safron, Klimaj, et al., 2021; Stanley \& Lehman, 2015). REBUS is further characterized by the overarching goal of combining "neurophenomenology" (Carhart-Harris, 2018; Rudrauf et al., 2003; Sandved Smith et al., 2020) with the tools of computational psychiatry (Friston, Redish, et al., 2017) in ways that could dramatically alter clinical practice.

The foundational premise of REBUS is that activation of 5-HT2A receptors promotes excessive excitability for deep pyramidal cells (Figure 1), especially with respect to higher levels of cortical hierarchies-understood as inner portions of deep generative models entailed by nervous system organization. According to REBUS, 5HT2a agonism of deep pyramidal neurons results in the implicit relaxation of high-level priors as overly-excited neurons fail to synchronize, so making it more likely that nervous systems will be updated by unsuppressed ascending prediction errors from the external world. This removal of top-down priors then affords a greater latitude for belief updating throughout the hierarchy.

Here, we propose an alternative account of the effects of psychedelics that is in many ways compatible with REBUS, albeit with some important differences. In what follows, we introduce a unified model of $\underline{\text { Altered }} \underline{B}$ eliefs $\underline{\text { Under P}}$ sychedelics (ALBUS) in

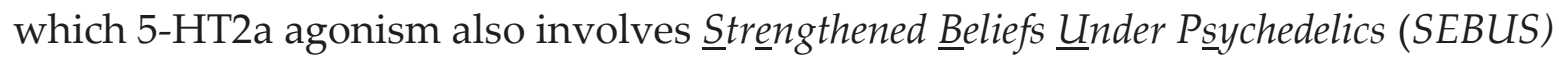
effects (Figures 1, 2, 3), particularly at intermediate levels of abstraction associated with conscious experience (Aru et al., 2019, 2020; O’Reilly et al., 2017; Prinz, 2017; Safron, 2020a, 2021a, 2021b). In terms of canonical microcircuits for HPP (Bastos et al., 2012), we propose that distributions of receptors in cortical laminae (Willins et al., 1997) suggest the following hypotheses for 5-HT2aRs agonism:

1. Low-to-moderate levels of stimulation of L5 excitatory pyramidal neurons may strengthen (SEBUS) - rather than weaken (REBUS) - complexes of synchronous activity to which these neuronal populations contribute via thalamocortical oscillations (Aru et al., 2019). This will have the effect of strengthening entailed 
beliefs, functionally understood as implicit and sometimes explicit Bayesian prior expectations, or "predictions" with respect to HPP.

2. Low-to-moderate levels of stimulation of L2/3 inhibitory interneurons will also suppress ascending sensory prediction-errors, so decreasing their influence on updating prior expectations. This could have the effect of further shielding (possibly strengthened) beliefs from disruption by inconsistent evidence.

3. Moderate-to-high levels of stimulation of these neurons may produce beliefrelaxation either via paradoxical disinhibition (Carhart-Harris \& Friston, 2019), by conflicting predictions (Pink-Hashkes et al., 2017), or by inducing novel biophysical regimes that diverge from past histories of shaping by experience.

4. Either REBUS or SEBUS effects may emerge indirectly as a function of psychological expectations regarding altered states.

Based on these mechanistic and psychological considerations, we propose that REBUS effects may often also involve SEBUS effects. Perhaps most compellingly, SEBUS effects may provide the most straightforward account of folk psychological descriptions of psychedelics as "mind manifesting" and "consciousness elevating" in terms of allowing contents to become more readily consciously accessible.

We believe ALBUS can provide a "minimum unifying model" for understanding psychedelics (Wiese, 2020), with various combinations of SEBUS and REBUS effects at varying (and heterogenous) hierarchical levels providing a potentially sufficient conceptual lexicon for describing how belief dynamics may be altered under different circumstances. That is, we do not intend on supplanting theories that exist or will be developed in the future, but instead are proposing a candidate set of models and principles by which other models can more readily be brought into conversation and made accountable to one another. If all we are doing is suggesting that it could be productive to think of different ways in which beliefs may be strengthened and/or relaxed, then ALBUS runs the risk of being nearly empty of content, or trivially true. However, we believe this risk is averted in focusing on the particular ways in which beliefs may be strengthened and/or relaxed within the context of understanding brains as hybrid computational systems (e.g. posterior cortices as autoencoding heterarchies; hippocampi as high-level controllers and predictive sequence memories; frontal lobe striatal-cortical loops as meta-learning systems; etc.). While our particular models may be questioned, the core claim of ALBUS is that we can meaningfully specify such a computational description for nervous systems using the language of machine learning, with further clarity obtainable through FEP-AI's account of minds as evolving ecosystems of beliefs/predictions (and the ways they may be strengthened or relaxed) for value-driven agents. In this manuscript we specifically focus ALBUS on classic psychedelics whose effects are substantially mediated by 5-HT2a receptors. However, in what follows, we hope to show that the study of psychedelics within the ALBUS framework has broader implications for understanding varieties of conscious (and 
unconscious) experiences, including phenomena such as pathological conditions, various meditative states, and even the nature of dreaming.

\section{Neurophenomenological models of psychedelics}

In what follows, we introduce a series of novel neurophenomenological models, whose complexity may be required for beginning to adequately account for psychedelic-related belief dynamics. With Figure 1, we describe how we could expect either REBUS or SEBUS effects with 5-HT2a agonism. With Figure 2, we describe how subjective experience may require models that go beyond the simplicity/elegance of hierarchical predictive processing (HPP) as usually understood in terms of a singular algorithm for Bayesian inference. With Figure 3, we extend this model to psychedelic phenomenology, suggesting ways that different combinations of REBUS and SEBUS phenomena could occur with different doses of 5-HT2a agonists. Finally, with Figure 4, we provide a detailed model of how different levels of 5-HT2a agonism may alter highlevel cognition as mental simulation. This model of the stream of experience depicts thought as a kind of covert behavior, for which detailed understanding of the hippocampal/entorhinal system may be critically important for understanding the levels at which cognition and action may be most powerfully orchestrated (Çatal et al., 2021; Dohmatob et al., 2020; Koster et al., 2018; Safron, Çatal, et al., 2021).

Aspects of these models may be debated, which we encourage, both in terms of helping us to update our beliefs to more faithfully reflect the world, and also in that we hope to work in collaboration with others to construct increasingly detailed and accurate models of the impacts of psychedelics on cognition. And in this case, we are forced to attempt to model consciousness itself in terms of the processes that generate different kinds of subjective experiences and all of their particular qualities. Without this kind of detailed understanding, we will likely fail to achieve sufficiently constrained models for reliability for both scientific theorizing and clinical interventions. While this might seem like a hopeless task, given our present state of scientific understanding, we believe a sufficient degree (or critical mass) of knowledge has accumulated such that we may now make unprecedented progress with respect to these hardest of problems, if we are able (and willing) to bring together diverse perspectives. However, with respect to our hopes of making ALBUS a unifying model for understanding psychedelics, the following models and their particular details are more intended to be illustrative, rather than definitive. To the extent these models accurately account for mechanisms contributing to various kinds of psychedelic experiences, they can be considered to provide support for the ALBUS approach. Although if particular claims may be found lacking in plausibility or evidential support, with respect to our intentions, we hope these are construed as opportunities for 


\section{discourse and collaboration on the project of trying to find a coherent conceptual account of psychedelic action.}

Figure 1 (below): SEBUS and REBUS effects in hierarchical predictive processing (HPP). The left image depicts mechanisms of inference and updating in cortical hierarchies (Safron, 2020a, 2021b), considered before the administration of 5-HT2a agonists. Light purple circles indicate deep pyramidal neurons (layer 5), thought to encode predictions (or priors) via their ability to form large-scale synchronous complexes, partially due to the ability of these units to form re-entrant loops with the thalamus. Dark purple rectangles indicate higher levels of cortical hierarchies (e.g. amodal cortices and associated networks), encoding more abstract high-level beliefs regarding sources of prior expectations over the causal structure of the world (including oneself and others). Red shading indicates rhythmic complexes of synchronized neuronal activity forming at beta frequencies ( 13-30 Hz), where these probabilistic beliefs are propagated down cortical hierarchies towards primary sensory modalities, indicated by red arrows, where degree of thickness corresponds to relative strengths for these prior expectations. White circles, in contrast, indicate superficial pyramidal neurons (L2/3), corresponding to expectancy-violations, providing a bottom-up flow of prediction-errors (generated at faster gamma frequencies; gray shading) as the only information passed up cortical hierarchies in predictive coding. The confidence associated with these prediction errors is known as "precision weighting", indicated by thickness of black arrows. Precision-weighting determines the degree to which prediction errors update hierarchically higher predictions, and so change those prior beliefs to more accurately account for sensory observations. Ascending prediction errors are depicted as thinner grey arrows when they are attenuated by descending predictions. A REBUS effect (bottom right) would involve a weakening of priors (indicated by smaller beta complexes with thinner red arrows), which allow more sensory observations to reach deeper portions of the brain as prediction errors fail to be suppressed (indicated by more numerous grey shaded regions and somewhat thicker grey arrows). A SEBUS effect (top right), in contrast, would involve both a strengthening of priors (indicated by larger beta complexes with thicker arrows), which are depicted as being more effective at suppressing ascending prediction errors (indicated by thinner grey arrows). An additional SEBUS effect is depicted in terms of thinner arrows for all prediction-errors, which could be functionally understood as a kind of default reduction in precisionweighting and reduced updating from sense data. Since contributions to implicit (and sometimes explicit) Bayesian beliefs are a function of the relative precision from top-down prediction and bottom-up prediction errors, this attenuation of the gain on sensory observations would be functionally understood as providing prior expectations with greater (or stronger) influence on inferences and updating. In this way, psychedelics may not only involve strengthened prior expectations, but such beliefs may be given further power by being less likely to be contradicted by inconsistent sense data. 


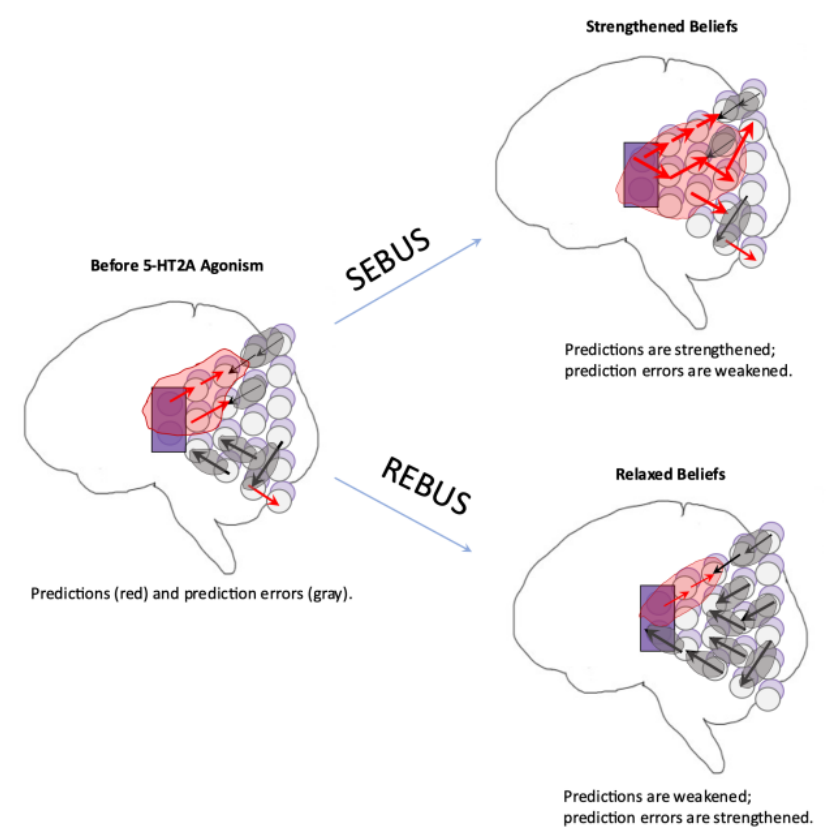

Figure 2 describes a progression of information being integrated into increasingly large and encompassing (but more slowly evolving) complexes of synchronous neural activity. This multi-scale nested hierarchy is proposed to afford phenomenal consciousness due to the ability of alpha frequencies to integrate information from all sensory modalities, organized according to egocentric reference frames. Across scales, synchronous neural activity is assumed to enable "communication through coherence" (Deco \& Kringelbach, 2016; Fries, 2015), computationally understood as the establishment of a joint belief from whatever information is capable of being exchanged on the timescales of formation for these meta-stable attracting states (Safron, 2020a, 2021b). The inverse relationship between the size and speed of rhythms may be a necessary consequence of the differential challenges of creating coherent oscillatory modes for networks of varying sizes (Buzsáki \& Watson, 2012). A visuospatial sketchpad - and "mind's eye," or "Cartesian theater" (Safron, 2021a) - is depicted as centered on posterior medial cortices, which have been demonstrated to both constitute major sources of alpha synchronization as well as being implicated in generating visual imagery and awareness (Freton et al., 2014; Sreekumar et al., 2018; Xie et al., 2020). While not depicted, an additional source of conscious experience may be found in lateral parietal cortices in terms of somatospatial processing, which may couple with visuospatial modalities in complex ways that would 


\section{influence things like awareness of embodied selfhood, coherent tracking of causal}

sequences, and senses of ownership for actions (Darby et al., 2018). If such couplings are disrupted, this could potentially contribute to the generation of a variety of anomalous inferences ranging from hallucinated external voices to the perception of non-existent entities. Such perceptions of other agents are sometimes reported with psychedelic experiences (Davis et al., 2020), and here we describe a mechanistic (and naturalistic) account of the processes that might contribute to their generation.

Figure 2 (below): Integration of sense data into a coherent field of experience. Predictive processing cortical hierarchies from Figure 1 are depicted as trapezoidal shapes with purple shaded rectangles at their apex. The top, bottom left, and bottom right trapezoids indicate respective hierarchies over somatic, auditory, and visual modalities. Dark red shading indicates smaller and faster forming beliefs from synchronized neural activity communicated at higher beta frequencies ( $20-30 \mathrm{~Hz})$, and light red shading indicates larger and slower forming beliefs communicated at lower frequencies $(\sim 13-20 \mathrm{~Hz})$. Smaller and faster beta oscillatory complexes are depicted as sometimes nested within larger and more slowly synchronizing beta rhythms, so enabling hierarchical modeling of more complex events evolving across multiple spatiotemporal scales. Blue shading indicates even larger and more slowly unfolding alpha rhythms ( 7-12 Hz), providing yet another level of hierarchical depth for deep temporal world modeling (including with respect to self-processes). The left-most panel depicts modeling via fast and small beta complexes, with entailed representations constituting lower-level features such as vibratory patterns for hearing, somatosensation, and fine-grained visual information. The middle panel depicts this information being brought together into more complex compositions, including object information as modeled by each modality. However, these entailed objects are not intended to indicate conscious experiences, which is reserved for the rightmost panel in which modalities can be coherently integrated via egocentric reference frames (i.e., seeing one's hand reaching out to grab an apple from the branch of a tree). Please see Safron (2020a, 2021a, 2021b) for more details on the neural and computational bases of phenomenal (and access) consciousness. Note: While we believe this account of the emergence of subjective experience is illuminating for contextualizing the effects of psychedelics, our proposal of altered beliefs under psychedelics (ALBUS) as involving both strengthened and relaxed beliefs does not depend on the particular details of these models of conscious perception.

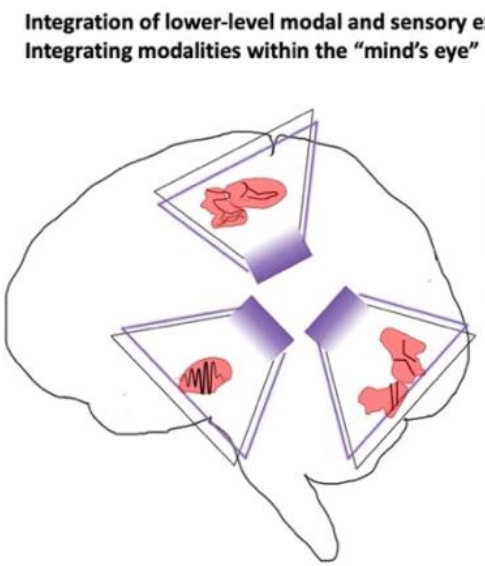

Fast beta (red).

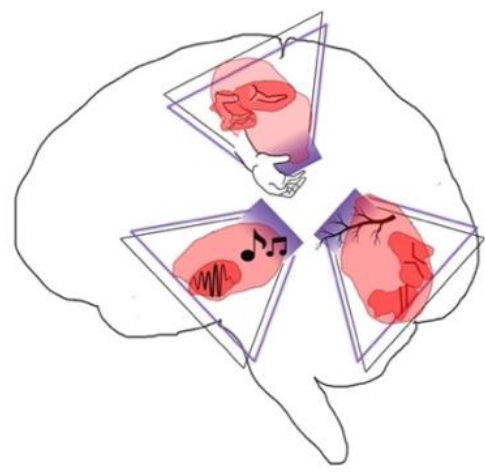

Fast beta (red) within slower beta complex (lighter red).

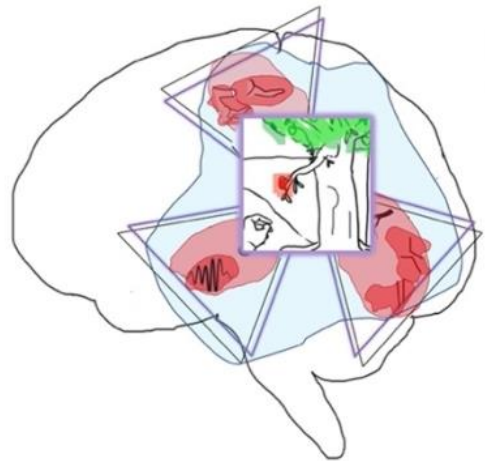

Beta (red) nested within alpha (blue). 
With respect to our previously imagined nature-immersed agent, we may think of hierarchical predictive processing (HPP) mechanisms as contributing to the perception of an apple by allowing more abstract patterns to be inferred (or predicted) from sense data. However, experience has multiple sensory aspects with different associated qualities, which are brought together in multiple ways in various levels of detail. In Figure 2, we suggest that an apple could be consciously experienced if multiple sensory hierarchies can synergistically combine their complementary sources of information to obtain more powerful inference, and that these inferential capacities may be further enhanced if given organization by egocentric perspectival reference frames, which may be required for sufficiently coherent experiences such that we can be made aware of and report on them, or perhaps are necessary for any consciousness to be generated whatsoever (Safron, 2020a, 2021b).

Figure 3 describes REBUS and SEBUS effects in the contexts of imagination and perception. While imagination can involve either $1^{\text {st }}$ or $3^{\text {rd }}$ person reference frames, only $3^{\text {rd }}$ person perspectives are depicted to indicate their necessity for constructing objectified selfhood and reflexive meta-aware self-consciousness (i.e., moving from an experiencing "I" to a Jamesian "me") (James, 1890; Metzinger, 2010). Non-dual awareness and dissociative (and potentially pathological) states associated with psychedelics and meditative experiences could be understood as arising from a breakdown of such processes of self-objectification (Ciaunica \& Safron, 2022; Safron, 2021a). Complexes of neural activity synchronized at beta frequencies are depicted as corresponds to the generation of specific beliefs (as predictions, or communication of Bayesian prior expectations), with alpha frequencies corresponding to integration into egocentric reference frames (also as predictions/priors). Contributions of posterior medial cortices to alpha power are notable in that this region has been shown to contribute to the establishment of coherent egocentric perspectival reference frames, likely partially due to receiving neck stretch receptor information from the mamillary bodies and head motion information from the vestibular apparatus (Papez, 1937; Snider and Maiti, 1976; Sharp and Koester, 2008; Brewer et al., 2013; Dillingham et al., 2015; Wijesinghe et al., 2015). Reducing coherence in signaling from these regions could have the effect of destabilizing egocentricity for selfhood on multiple levels, potentially contributing to the attenuation of more extended self-processes while preserving sufficiently coherent models of embodiment for maintaining some degree of conscious perception (Safron, 2021a). Speculatively, such a partially dissociated state could allow for elevated absorption with respect to both imagination and perception (Csíkszentmihályi, 1991; Ott et al., 2005; Tellegen, 1982).

It is at this point that we are beginning to consider phenomenology in terms of the particular textures of experience. In this account, the strength of rhythmic complexes of neural activity is suggested to reflect the strength of beliefs, some subset of which correspond to conscious subjective experiences. We suggest SEBUS effects 
may correspond to enhanced "vividness" and/or the richness of details for experiences, potentially reflecting respective consciousness level and conscious contents. We further propose a model focusing on rhythmic complexes over posterior lobes as potential realizers of phenomenal consciousness, understood as the iterative estimation of likely sensory states, conditioned on a causal world model. However, this should not be taken to suggest that we are providing a sufficient account of the nature of conscious perception. For example, various forms of attentional selection (involving additional neural systems) will certainly influence both the vividness and richness of percepts. Here-and elsewhere (Safron, 2020a, 2021b) - we indeed suggest that potentially sufficient mechanistic bases for consciousness may still be realized by a set of interacting rhythmic processes that entail the inversion of generative models over sensoriums for embodied-embedded agents. However, this claim should not be taken as either a) constituting part of the "hard core" of the ALBUS framework, or b) implying that we believe that frontal lobes are unimportant for phenomenology. Indeed, as we will describe in greater detail below, functional decoupling of frontal cortices from the rest of the brain could explain many aspects of psychedelic experiences.

Figure 3 (below): REBUS, SEBUS, and ALBUS effects in brain and mind. These images depict how neurological and phenomenological processes may be altered under different kinds of psychedelic interventions. Panels on the left indicate perception-grounded sensation, which is always necessarily experienced from a $1^{\text {st }}$ person point of view due to locations of sensors on the body. Panels on the right indicate imaginative perception generated from memory decoupled from sensation, organized according to a $3^{\text {rd }}$ person perspective. The extent of shaded complexes of rhythmic neural activity is meant to indicate degrees of coherent integration associated with various frequency bands. For the panels on the left, alpha and beta complexes extend further down towards primary modalities to indicate information flows being constrained by sense data to a greater degree. For panels on the right, alpha and beta complexes are centered in deeper portions of the brain, so realizing imaginative processing as the unfolding of consciousness with reduced tethering by information from the external world. a) Top row indicates unaltered consciousness. b) Second row indicates what might be observed under smaller psychedelic doses with strictly REBUS effects (i.e., relaxed beliefs) - which may be highly unlikely to occur - with all beliefs being relaxed, depicted as less extensive alpha and beta complexes. The expected subjective effects from such modifications are depicted as including greater sensory details from perception, but with less perceptual vividness. Discrepancies between these predictions with actual subjective reports indicates that this model on its own may not be adequate for accounting for psychedelic experience. If all priors were relaxed for cortical generative models, then we would expect this to also apply to intermediate hierarchical levels at which perceptual synthesis and sensorimotor-grounded cognition may be realized (Barsalou, 2010; Prinz, 2017; Safron, 2021a; Varela et al., 1992). c) Third row indicates what might be observed under smaller doses with strictly SEBUS effects (i.e., strengthened beliefs) - which could be the case for low-to-moderate levels of 5-HT2a agonism - mechanistically depicted as the inverse of REBUS. This is subjectively depicted as including greater perceptual vividness, and details being more likely to match the expectations of a potentially richer imagination, with the beginnings of psychedelic phenomenology in the form of fractal patterns and quasi-synesthetic percepts. [Note: Synesthetic phenomenology could be explained by either a pure SEBUS model (as strong cross-modal priors) or in terms of REBUS effects where non-strengthened beliefs are afforded greater communicative capacity when normal high-level beliefs are relaxed.] d) Fourth row indicates an admixture of REBUS and SEBUS effects (i.e., ALBUS), involving both strengthened beta and relaxed alpha synchrony, subjectively depicted as entailing both greater perceptual vividness and more intense psychedelic phenomenology, including the beginning of altered self-models. e) Fifth row indicates REBUS/SEBUS effects under extreme levels of 5-HT2a agonism, including the breakdown of organization of experience according to coherent self-models. Such highly 
altered states could be understood as a kind of "ego death" as sometimes described by "psychonauts" (Martial et al., 2021), and which is normally only reported by meditative adepts, with naturally occurring mystical experiences (James, 1902; Safron, 2016), or in individuals suffering from severe forms of psychosis (cf. disconnection hypothesis of schizophrenia). Please note that the neither the basic premise of ALBUS nor subsequently described manifestations of psychedelic alterations depend on these particular details being accurate with respect to the neural bases of perception and imagination. Rather, our core claim is that mechanisms of predictive processing suggest that primarily SEBUS effects should be expected with lower levels of 5-HT2a agonism, and also that REBUS effects are unlikely to be observed in isolation without the concomitant strengthening of perceptual beliefs.

REBUS, SEBUS, and ALBUS: Phenomenology with different degrees of 5 -HT2A agonism

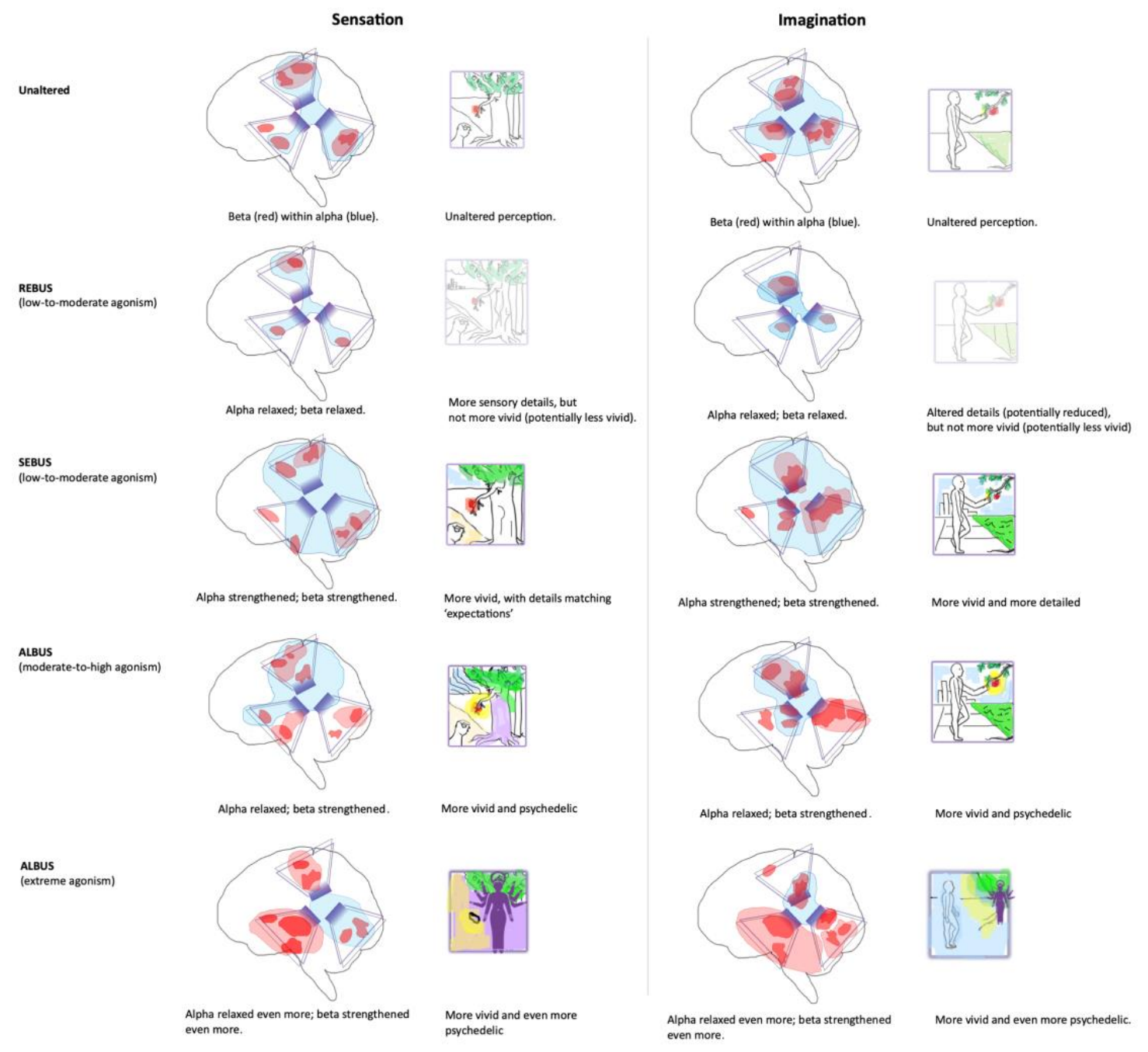

Figure 4 describes six different regimes of cognition, organized with respect to levels of 5-HT2a stimulation expected with various psychedelic interventions or similar endogenously-generated states: "Unaltered," "Microdose," "Threshold dose," "Medium dose," "Heroic dose," and "Extreme dose". Hippocampally-mediated orchestration of dynamics are depicted as the highest level of action selection in the brain, indicating overall integrated functioning of attracting states for the organism (Çatal et al., 2021; 
Safron, 2021a; Safron, Çatal, et al., 2021). For each regime, two episodes of $~ 1-3$ seconds in duration are shown as sequences of imaginative and perceptual states, with the second episode meant to indicate a stream of experience generated subsequent to termination of the first one. Depictions of the brain and associated experiences involve the model of phenomenal consciousness (and its alterations) from Figure 3, but expanded to include orchestration by theta rhythms (yellow shading) from the hippocampal/entorhinal system. "Cognitive maps" in the hippocampus are depicted underneath each brain as hexagonal tilings of space, through which potential future trajectories are indicated as green shaded hexagons, with present-estimated trajectories indicated by red hexagons. Two maps are shown to indicate potential functional divisions between anterior and posterior portions of the hippocampus, which respectively more strongly couple to frontal and posterior cortices (Faul et al., 2020). Anterior hippocampal maps show multiple routes through space, which are selected at each moment (darkest green) based on expected value of choosing that route (Kay et al., 2020; McNamee et al., 2021; Stachenfeld et al., 2017). Posterior maps, in contrast show a single route through space, corresponding to the perceived path taken and encoded in memory, with the most intense red shading indicating estimates for the present moment of experience, and with this activity gradually fading across subsequent timesteps. Notably, while these trajectories are most commonly understood with respect to navigation through physical space, it is increasingly suspected that this core system for localization and mapping was repurposed for the sake of high-level cognition as navigation through generalized space (including conceptual spaces) (Gothoskar et al., 2019; Hawkins, 2021; Kaplan \& Friston, 2018; Safron, Çatal, et al., 2021; Whittington et al., 2019).

Below these maps, within each theta cycle, two frames of experience are depicted as unfolding at alpha frequencies. [Please note, these alpha-synchronized experiential frames are not meant to directly align with theta from the hippocampal maps above them; while the first frame may be more likely to be influenced by counterfactual imaginings orchestrated by the anterior hippocampus, each particular moment of experience could be a function of either imagination or perception depending on numerous factors (e.g. degree of driving inputs from the senses).] The number of theta cycles in each row indicates tilings of (generalized) space along which trajectories may be planned and recorded in memory, which are shown as variable length sequences due to different levels of 5-HT2a agonism. These chunked sequences could be understood as Edelman's "remembered present" or James' "specious present" where "now" has inherent temporal thickness as past moments both contextualize and are recontextualized by future moments of experience (Edelman, 2001; Varela, 1999).

Two sequences (Episode 1, Episode 2) are depicted for each level of dosing, where different cognitive regimes involve varying degrees of coherence (and potentially conscious access/remembering) maintained across time when separated by resetting/re- 
tiling events. The precise extent of these trajectories through mental spaces would be influenced by "circuit-level" functional properties such as degrees of neuromodulation (O'Callaghan et al., 2021; ul Haq et al., 2016), with both 5-HT1a and 5-HT2a receptor agonism being capable of inhibiting the sharp-wave ripple events indicative of re-tiling space for different modes of sense making with alternative sets of potential actions. Alternatively, such hippocampal resetting could occur via surpassing thresholds for cumulative prediction error, such as might be expected as uncertainty builds with respect to the ability of a given set of behavioral policies to be effectively realized through enaction. 5-HT2a agonism may impact the extent of these predictive and remembered 'task' sets both by inhibiting hippocampal resetting mechanisms directly, as well as by allowing for more or less coherent sequences of perception, so influencing degrees of overall prediction error accompanying mental simulations.

An often used proxy for psychedelic phenomena in the rodent literature involves detecting increased rates of "head twitches" (de la Fuente Revenga et al., 2019; Halberstadt et al., 2020), which we here suggest may correlate with hippocampal resetting/re-tiling events (Domenico et al., 2021; Widloski \& Foster, 2022). We specifically hypothesize that such correlations could result from head twitching either directly stimulating the establishment of new hippocampal attractors, or possibly reflecting (not necessarily successful) attempts to prevent such resetting, perhaps understood as a kind of perseverance or epistemic 're-gripping' within active inference (Friston, FitzGerald, et al., 2017; Hesp et al., 2020; Safron \& Sheikhbahaee, 2021). If such speculative functional mappings are accurate, then nearly all studies involving headtwitch measures may involve relatively high levels of 5-HT2a agonism, which while providing many opportunities for testing REBUS models, may also suggest a somewhat misleading picture of the effects we might expect along a fuller dose-response curve. Various forms of metacognition and self-consciousness are made possible to varying degrees based on the extent of these cognitive sequences, where coherent contextualization of experience influences the extent to which such percepts are accessible and reportable both within and across episodes. If different degrees of 5HT2a agonism influence such processes, then this would constitute a powerful source of both intra- and inter-individual differences in cognition and behavior. Theoretically, such levels of functional neuromodulation could vary both genetically and epigenetically as mechanisms for evolutionarily-adaptive life history strategy selection.

Figure 4 (below): Cognition as altered under different levels of 5-HT2a agonism. Please see main text (above) for more details. a) The top set of rows (Unaltered) show cognition unfolding with low levels of 5-HT2a agonism. b) The second set of rows (Microdose) show a slightly more extended sequence with somewhat increased perceptual clarity and continuity across percepts. This may correspond to the mild 5-HT2a agonism provided by elevated CO2 or lactic acid accompanying physical activity (Buchanan et al., 2015), with slightly increased experiential absorption as coherently focused consciousness across time. c) The third set of rows (Threshold dose) show even more extended sequences with even greater vividness, detail, and absorption, with the beginnings of more creative associations (e.g. the apple pie). Physiologically, such levels of agonism might potentially be achieved non-pharmacologically with 
even more intense engagement with physical activities. This level of neuromodulation is not yet strongly psychedelic, and may potentially indicate more of an "active coping" strategy in the face of threat, which may correspond to altering cognition for more exploration or exploitation depending on numerous contextual factors (Carhart-Harris \& Nutt, 2017; Gopnik et al., 2017; Hills et al., 2010). d) The fourth set of rows (Medium dose) show the beginnings of psychedelic phenomenology as normally understood, with the number of theta cycles (and cognitive operations) in each sequence beginning to lessen due to reduced coherence. Imaginings become increasingly creative and become closer to perception in vividness, which here shows an additional mnemonic association (i.e., one's mother in relation to apple pie) that might not otherwise be accessible under less altered conditions. Under the conditions typical of evolutionary history, this level of agonism might only be exogenously achieved with extreme situations as might accompany reproduction, ritual, or combat, potentially involving endogenous DMT systems (Brouwer \& CarhartHarris, 2020; Martial et al., 2021; Safron, 2016). e) The fifth set of rows (heroic dose) show further truncated sequences with even more intense psychedelic phenomenology, near complete blurring of imagination and reality, and altered selfhood. This conjunction of unusual patterns of cognition with high levels of perceptual vividness (and potential impacts on memory) would provide a major opportunity for updating internal working models, as observed with the powerful therapeutic changes observed with psychedelic interventions (Johnson et al., 2019). It is unclear the extent to which such levels of agonism reliably occurred within environments of evolutionary adaptation outside of shamanistic practices, extreme rituals (e.g. breathwork, initiation rites, sun dance ceremonies), or perhaps orgasm and/or birthing (Safron, 2016). f) The sixth set of rows (Extreme dose) show radically altered cognition involving the visualization of archetypical images (i.e., core priors) and a near complete breakdown of the processes by which coherent metacognition and objectified selfhood are made possible. Over the course of human evolution, such experiences may have only occurred with the aid of exogeneous sources of 5-HT2a agonism, severe psychotic states, and possibly near death experiences (Martial et al., 2019).

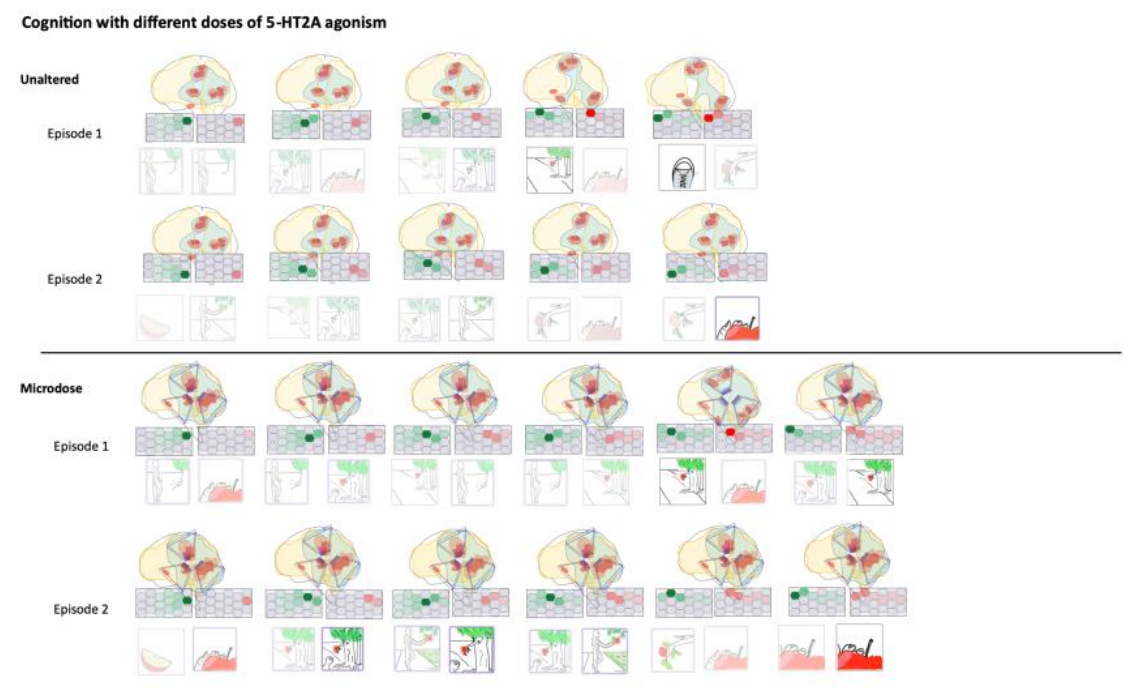



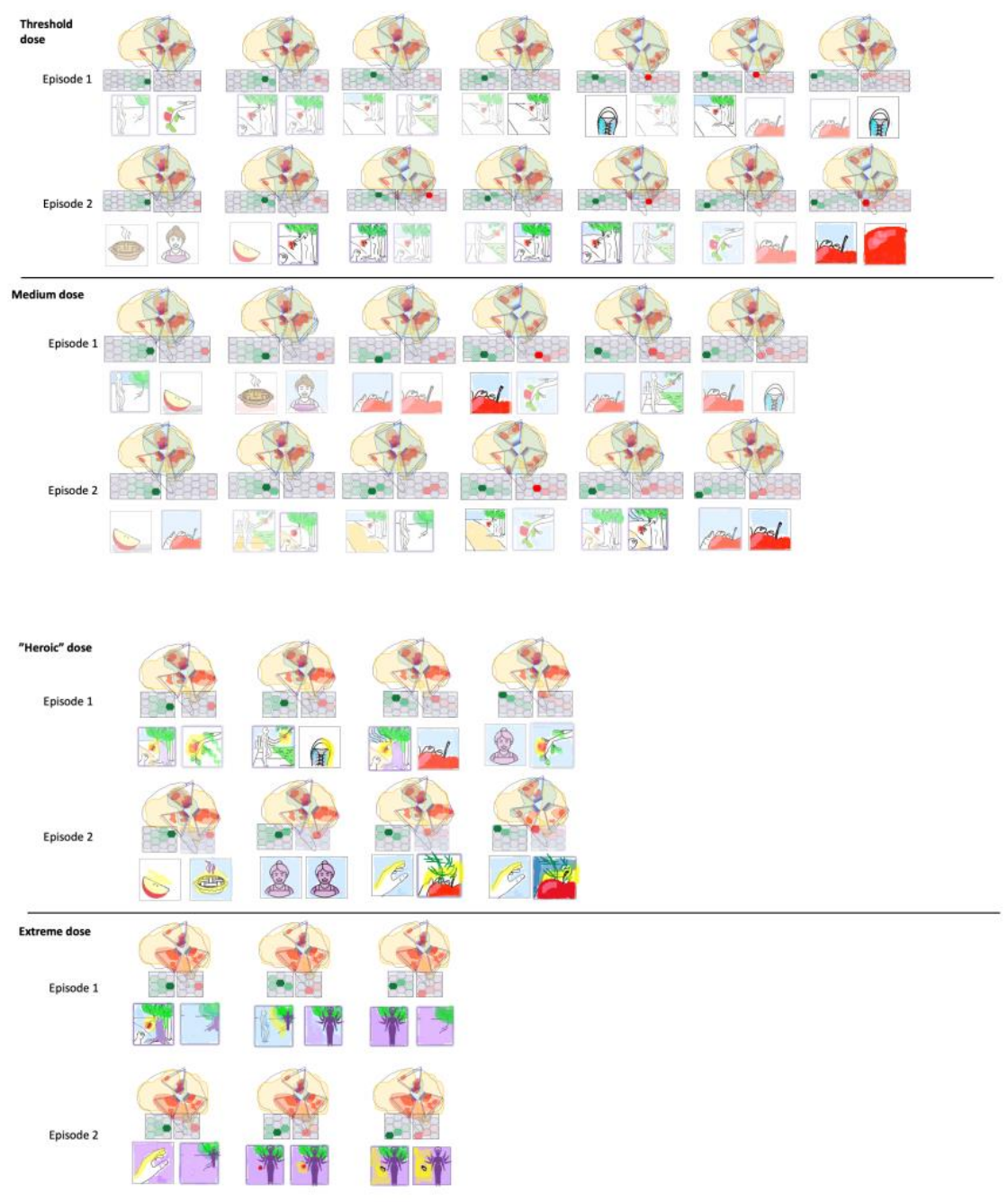
While these figures represent our best attempt at contextualizing psychedelic phenomena within the context of cognitive (computational) neuroscience, the ALBUS framework does not depend on the accuracy of any particular model described here. Rather, we are hoping to illustrate the kind of thinking required if we are going to bring a neurophenomenological perspective to psychedelics in ways that could meaningfully inform basic research and clinical practice. While the following models build upon each other in terms of their assumptions, they are also modular in that both a) our earlier models do not depend on the accuracy of our later models, and b) our more complex models could be multiply realizable by different combinations of component processes. In this way, our particular claims can be taken on (or not) "a la carte" based on individual sensibilities. However, if the models described in Figure 4 were found to be largely accurate depictions of the unfolding of the stream of consciousness and associated cognitive processes, then ALBUS may represent the first unified paradigm for understanding psychedelic phenomena and varieties of conscious experiences more generally. That is, while this may seem like an excessively bold claim, we believe the progression of regimes described in Figure 4 could potentially not only apply to different levels of 5-HT2a agonism, but could also be used to model various clinical conditions (cf. the "psychotomimetic paradigm"), the progression from sleeping to waking and back again, or degrees of lucidity within dreams, or other progressions such as cognitive development and decline (cf. Lewy body dementia, "terminal lucidity").

The ALBUS framework is intended to provide a common basis for integrating models and associated findings from other paradigms, whether emphasizing relaxed beliefs (Carhart-Harris \& Friston, 2019), opening attentional and perceptual thalamic filters (Preller et al., 2019), or altering cortical processing by disrupted coupling with integrative structures such as the claustrum (Doss et al., 2021). Apart from REBUS, other accounts of psychedelic action have tended to remain uncommitted in describing effects on the levels of computational functions and their potential algorithmic realizations. While the ability to separately analyze systems on multiple levels of analysis is invaluable, we also believe that cross-level connections can also be leveraged as converging lines of evidence and source/constraint for hypothesizing (perhaps akin to filling in a multi-dimensional crossword puzzle). More specifically, ALBUS would suggest that machine learning (and FEP-AI) could provide a kind of "lingua franca" for shared (and potentially synergistic) sensemaking across different theories. For example, by describing perceptual synthesis in terms of an auto-encoding hierarchy, ALBUS could help connect thalamic gating models with recent proposals regarding the computational bases of consciousness and the conditions under which experience is more or less "ineffable" (Bengio, 2017; Ji et al., 2023). With respect to Figure 4, increased ineffability could correspond to situations in which the richness of experiences at the 
level of perceptual synthesis are enhanced, but where orchestration into coherent sequences is compromised. Another example could be found in drawing connections between claustral integration models and proposals where frontal lobes subserve integrated error-detection and reality-monitoring functions (Gershman, 2019; Lau et al., 2022). In terms of the models presented here, we could think of psychotomimetic cognition as arising through compromised abilities to form coherent (contextualizing) sequences of conscious states, and potentially even disrupted frontal-parietal coupling as forming a basis for hallucinations (cf. efference copies and corollary discharges). However, while we believe that we have described well-evidenced models of sufficient power to characterize many psychedelic-related phenomena, our goal is not a definitive exhaustive model of psychedelic and related experiences. Rather, by both emphasizing mechanistic diversity and conceptual unity (in terms of concepts machine learning, and potentially FEP-AI), our main hope for ALBUS is to facilitate productive conversations across perspectives that have non-overlapping strengths and weaknesses (and thereby potential for inferential synergy).

\section{ALBUS and Complex Causation: SEBUS via REBUS; REBUS via SEBUS}

REBUS emphasizes L5 pyramidal neurons (Carhart-Harris \& Friston, 2019), suggesting that increased excitability from 5-HT2A agonism results in asynchronous activation modes, and thereby relaxed beliefs through attenuated coherence. This suggestion provides a potentially sufficient account for reduced alpha power and ego dissolution associated with psychedelic states (Smigielski et al., 2019). In a similar spirit to this paradoxical reduction in coherent signaling via excessive excitation, the inhibitory-interneuron mechanism described above as a source of SEBUS effects may be challenged. That is, increasing the excitability of superficial interneurons may not necessarily inhibit ascending prediction errors in those layers, but could potentially have the opposite result via indirect disinhibitory dynamics (Friston, 2019; personal communications with Safron). However, we suggest these kinds of desynchronization may be more likely with moderate-to-high levels of stimulation, and not necessarily with smaller doses of psychedelic compounds.

Perceptual illusions could be illustrative in terms of distinguishing between REBUS and SEBUS effects. Susceptibility to these misleading percepts is well-explained by HPP in terms of perception understood as probabilistic inference. If our perception corresponds to our best guess for causes of sensory observations, given past experience, then these guesses can sometimes be mistaken. With illusions, stimuli constitute "adversarial attacks" on the generative models of our brain (Dujmović et al., 2020; Gershman, 2019; Jacob et al., 2021; Safron, 2020b), causing us to infer percepts that directly contradict sense data. However, our minds are capable of being tricked in this way because our perception is structured according to our prior expectations from (our interpretations of) past sensory experiences. According to a REBUS model, relaxation of 
these priors should raise illusions susceptibility thresholds, so making us more resistant to going down these perceptual garden paths. According to a SEBUS model, illusion susceptibility thresholds may be lowered, so making us even more likely to create these anomalous inferences. Based on the two mechanistic considerations described above, we suggest SEBUS effects are likely to predominate with low-to-moderate levels of 5HT2a agonism, and with some combination of SEBUS and REBUS effects at higher levels of stimulation for those pathways. Thus, we might expect increased illusion susceptibility with lower doses of psychedelics, but potentially decreased illusionsusceptibility with higher doses.

REBUS emphasizes the high concentrations of 5-HT2a receptors for deeper portions of generative models, suggesting that intermediate hierarchical levels associated with conscious perception could become strengthened as they are released from predictive suppression from hierarchically higher areas. This would be an example in which SEBUS phenomena form as an indirect consequence of REBUS effects. The inclusion of such looping causal cascades may make it difficult to establish whether SEBUS effects can occur independently of being driven by 5-HT2 stimulation. However, observing increased susceptibility for illusions involving low-level perceptual features - which may be less influenced by high-level expectations - with lower psychedelic doses could potentially provide stronger evidence for SEBUS mechanisms (as it is unclear that we should expect the excitation-induced desynchronization described by REBUS with low-to-moderate levels of 5-HT2a agonism).

Yet another example of a complex relationships between strengthened and weakened beliefs was proposed by Pink-Hashkes et al. (2017), where predictions form so readily that they come into conflict with each other and so result in a more uncertain-or entropic (Carhart-Harris, 2018; Carhart-Harris et al., 2014) - belief landscape. Under such a state of uncertainty, hallucinations and other psychedelic phenomena are suggested to result from compensatory efforts wherein anomalous predictions are strengthened in attempts to explain incoming sense data. In this view, SEBUS effects produce REBUS effects, which in turn produce further SEBUS effects. Alternatively, SEBUS effects (e.g. hallucinations) could also arise indirectly if relaxed beliefs at upper levels of cortical hierarchies reduce suppression of prediction-errors at lower and intermediate levels of organization, such as those involved in the kinds of perceptual and imaginative synthesis underlying conscious experience (Figures 2, 3). In this view, SEBUS effects would be the indirect result of REBUS effects. While such complicated models may seem to lack parsimony, unfortunately - or perhaps fortunately with respect to flexibility/adaptivity - such non-linear causal cascades may easily emerge from complex nervous systems.

Causal complexity could become even greater if we consider various forms of conscious and self-referential processing. For example, low-to-moderate doses of 5- 
HT2a agonism could generate strictly SEBUS effects at the level of cortical microcircuitry, yet produce multiple kinds of REBUS effects in belief dynamics:

1. Qualitative differences in processing resulting in individuals approaching experience atypically, so "relaxing" typical assumptions.

2. Expectations of atypical cognition causing such experiences to become more likely (cf. placebo and nocebo effects).

3. Explicit expectation of REBUS-like effects producing patterns of cognition characterized by enhanced open mindedness and creativity.

In these ways, while we believe the account of predictive processing described by REBUS may require additional details to account for the full range of psychedelic phenomena, we want to emphasize that we are not suggesting this theory should be abandoned in favor of SEBUS models. Rather, we suggest the way forward will involve combining both SEBUS and REBUS phenomena (including their potential interrelations), as well as additional neural process theories (Doss et al., 2021; Preller et al., 2019), into a broader framework of altered beliefs under psychedelics (ALBUS).

We propose that SEBUS effects are strongly suggested by the non-veridical nature of hallucinations, which may be straightforwardly understood as strong prior expectations overwhelming sensory evidence. A strictly REBUS account would suggest more veridical perception as being more straightforwardly based on raw sensory input from the world, rather than influenced by predictions. Further support for SEBUS effects may be found in similarities between psychedelic phenomenology and the varieties of images created with "Deep Dream"-style techniques (Suzuki et al., 2017; Szegedy et al., 2014). By having specific units in neural networks exert particularly strong top-down influences in the process of generating likely patterns of inputs, generated stimuli become predominated by representations of those particular features (e.g. creating images with biological characteristics depicted in unusual places). This would be an instance of strengthening, rather than weakening the beliefs entailed by those particular units in artificial neural networks; we suggest not dissimilar principles may be at play in biological neural networks when high levels of 5-HT2a agonism cause increased activity from L5 pyramidal neurons.

The increased subjective vividness and detail of experience with psychedelics would seem to suggest increased precision for sensory observations (i.e., more influence from prediction errors). However, models of consciousness centered on HPP suggest that perception and imagination are entailed by predictions, rather than sensory prediction-errors (Safron, 2020a, 2021b). Individuals may feel like they are seeing more details of the world as it is-which could be the case, depending on many factors-when in reality they may actually be experiencing their expectations more vividly, but less accurately. Observations of similar effects in the domain of ideas - cf. the "autonoetic" quality of mystical experiences (Barrett et al., 2015) - suggests that SEBUS effects may parsimoniously apply to belief dynamics at multiple levels of abstraction. 
We believe that SEBUS effects are further suggested by findings in which gamma power - thought to encode prediction errors - from primary visual cortex is inhibited with 5-HT2a agonism (Michaiel et al., 2019), as well as by associations between hallucinations and sensory deprivation (cf. Charles Bonnet syndrome or anomalous perceptual experiences sometimes reported with isolation tanks) (Sacks, 2013). While aspects of psychedelic phenomenology such as fractal perception may seem to suggest extremely complex dynamics, the mathematical symmetries underlying such forms may allow for their creation via extremely simple generative processes (Hutter, 2000; Schmidhuber, 2002). [In terms of the Free Energy Principle, isolating a prediction-errorminimizing system removes requirements for accurately predicting environmental causes, so allowing modeling efforts to focus on model-complexity minimization under a regime where thermodynamic and informational free energy converge (Friston, 2010). Theoretically, if sensory isolation results in greater optimization for complexity minimization, this could (seemingly) paradoxically result in fractal stimuli coming to dominate perception, which may seem to be complex, but may actually be relatively simple with respect to symmetries over the processes that create them (Safron et al., 2023).]

Overall, we propose that explaining the effects of compounds such as 5-HT2a agonists and NMDA receptor antagonists require a combination of SEBUS and REBUS models for understanding altered beliefs under psychedelics (ALBUS). SEBUSinvolving models may be necessary to sufficiently account for both the therapeutic and "psychotomimetic" effects of psychedelics. We suggest that strengthened-belief models may provide the most parsimonious explanation for how delusions and hallucinations are generated under both the temporary altered states of psychedelics as well as more enduring psychotic states (Wengler et al., 2020). As we hope to demonstrate with the detailed neurophenomenological models presented here (Figures 2, 3, 4), we believe a rather sophisticated analysis of cognition is required to adequately characterize ways in which beliefs may be altered under psychedelics (Friston et al., 2020; Hesp et al., 2020; Safron \& Sheikhbahaee, 2021).

Finally, while the neural and computational bases of consciousness remain extremely contentious, we believe there is no option but to seriously consider how different aspects of subjective experience may be mechanistically realized. While ALBUS may be challenged in terms of involving many detailed claims, we view this specificity as beneficial in allowing for both a) more constraints on theorizing, and b) more opportunities for testing (and perhaps falsification). Moreover, by making a large number of specific predictions based on highly detailed models, we may also find ourselves with an opportunity to indirectly speak to theories regarding the mechanistic bases of not only conscious access, but perhaps phenomenal consciousness itself (Johnson, 2021; Yaden et al., 2021). If theories of consciousness specifically predict multiple aspects of psychedelic phenomenology, then such correspondences may 
validly be interpreted as evidence for those models. We believe a satisfying explanatory account of consciousness requires establishing bridges across implementational, algorithmic, and computational levels of analysis (Marr, 1983), while richly connecting this multi-level understanding to core aspects of phenomenology. The specific claims of ALBUS are inspired by Integrated World Modeling Theory (IWMT) (Safron, 2020a, 2020b, 2021b), which draws upon Global Neuronal Workspace Theory (Dehaene, 2014), Integrated Information Theory (Tononi et al., 2016), and the Free Energy Principle to account for the generation of consciousness as a stream of experience from a subjective point of view. If accurate, we believe the models described here may provide a computational neurophenomenology of sufficient richness to begin to account for core features of subjectivity. Thus, psychedelics may end up living up to their promise for not only addressing the "easy" (and "real") problems of consciousness, but may even meaningfully speak to the Hard problem itself (Chalmers, 1995; Dennett, 2018; Nagel, 1974; Safron, 2020a, 2021a, 2021b; Seth, 2016; Seth \& Tsakiris, 2018).

\section{Which beliefs are we altering under what circumstances?}

[Please note, this section is especially technical, and can be safely skipped by lay readers.]

We have considered situations in which one might observe both directly and indirectly strengthened and relaxed beliefs in different combinations as a potential explanation for different varieties of psychedelic alterations. Such explorations can become difficult to follow (e.g. SEBUS effects via REBUS effects via SEBUS effects, etc.), and also point to a potential source of impasses in attempting to determine when we should consider what kinds of belief modifications, and how we can most fruitfully conceptualize them. While we will not be able to clarify these issues here, below we consider different modes of experience such as forms of imaginative and dream-like experiences (Table 1), kinds of beliefs as understood by the Free Energy Principle and Active Inference (FEP-AI) framework (Table 2), and different timescales of belief updating (Table 3). Table 1 can be viewed as an alternative formulation of the different combinations of perceptual experiences depicted in Figure 3. Table 2 attempts to provide a breakdown of different kinds of beliefs as might be described by an FEP-AIinformed computational psychiatrist attempting to construct an (agent-based) generative model for the sake of explaining and predicting likely patterns of behavior and cognition. Finally, Table 3 attempts to provide a more precise handling of the timescales over which beliefs may be updated. While these tables are highly technical and may seem overly complicated - and may be skipped by readers more interested in other sections - we believe this content is actually woefully underspecified with respect to what will be needed for sustainable progress in the clinical and basic science of 
psychedelics. For example, Table 1 begins to address phenomenological matters by discussing the vividness and/or richness of experience; whether these words point to natural kinds such as respective overall consciousness level and/or conscious contents is intentionally left ambiguous. In order to see the full potential of psychedelic science, ultimately, we will likely need to address these kinds of details with (hopefully wellresourced) interdisciplinary collaborations that bridge scientific, experiential, and even philosophical modes of being.

Some might object in the extent to which ALBUS draws upon FEP-AI, and may instead prefer a more ecumenical handling. This is not an unreasonable position, in that there is far more investment in mainstream machine learning, with FEP-AI representing a relatively small idea community. However, FEP-AI was specifically inspired by psychology and neuroscience, and has been under active development for many years in the context of computational psychiatry (Friston, Redish, et al., 2017; Safron \& DeYoung, 2021). Additionally, FEP-AI has associated mechanistic process theories (including HPP), which allow for likely physiological markers to be generated in simulations based on other data sources (e.g. choice behavior), which can then be compared against observations of real persons, so affording a powerful form of empiricism. Further, using techniques such as dynamic causal modeling, FEP-AI researchers have already conducted notable work demonstrating how REBUS and SEBUS effects might be observed in clinical conditions such as schizophrenia (Adams et al., 2013, 2022). Not only does such work in clinical populations have clear relevance for understanding some of the alterations induced by psychedelics as a "transient psychosis," but deploying these tools could reveal more detailed mechanistic understandings and potentially make way for the incorporation of a precision medicine approach to psychedelic therapy.

Table 1. Modes of experience.

\begin{tabular}{|c|c|c|c|c|}
\hline $\begin{array}{l}\text { Modes of } \\
\text { experience }\end{array}$ & $\begin{array}{l}\text { Neural processes } \\
\text { contributing to various } \\
\text { experiential modes }\end{array}$ & $\begin{array}{l}\text { Direct SEBUS } \\
\underline{\text { effects }}\end{array}$ & $\begin{array}{l}\text { Direct REBUS } \\
\text { effects }\end{array}$ & $\begin{array}{l}\text { ALBUS } \\
\text { (indirect and/or } \\
\text { admixtures of } \\
\text { SEBUS and } \\
\underline{\text { REBUS effects) }} \\
\end{array}$ \\
\hline $\begin{array}{l}\text { 'Normal' } \\
\text { sensation- } \\
\text { grounded } \\
\text { perceiving }\end{array}$ & $\begin{array}{l}\text { Multiscale rhythmic } \\
\text { attractors whose extent } \\
\text { allow for } \\
\text { coupling/enslavement } \\
\text { with/by sense data }\end{array}$ & (Unaltered) & (Unaltered) & (Unaltered) \\
\hline $\begin{array}{l}\text { Vivid and/or } \\
\text { rich (relative to } \\
\text { normal) } \\
\text { sensation- }\end{array}$ & $\begin{array}{l}\text { More powerful and/or } \\
\text { more complex attractors } \\
\text { coupled to sense data }\end{array}$ & $\begin{array}{l}\text { Potentially } \\
\text { accounted for if } \\
\text { increased firing } \\
\text { increases neural } \\
\text { synchrony and/or }\end{array}$ & $\begin{array}{l}\text { Difficult to } \\
\text { explain via } \\
\text { REBUS effects }\end{array}$ & $\begin{array}{l}\text { Potentially } \\
\text { accounted for if } \\
\text { relaxation of } \\
\text { beliefs at higher } \\
\text { levels causes }\end{array}$ \\
\hline
\end{tabular}




\begin{tabular}{|c|c|c|c|c|}
\hline $\begin{array}{l}\text { grounded } \\
\text { perceiving }\end{array}$ & & $\begin{array}{l}\text { the complexity } \\
\text { activation } \\
\text { dynamics }\end{array}$ & & $\begin{array}{l}\text { strengthening at } \\
\text { intermediate } \\
\text { and lower levels } \\
\text { of perceptual } \\
\text { synthesis }\end{array}$ \\
\hline $\begin{array}{l}\text { Veridical vivid } \\
\text { and/or rich } \\
\text { (relative to } \\
\text { normal) } \\
\text { sensation- } \\
\text { grounded } \\
\text { perceiving }\end{array}$ & $\begin{array}{l}\text { More powerful and/or } \\
\text { complex attractors } \\
\text { enslaved by sense data }\end{array}$ & $\begin{array}{l}\text { Difficult to } \\
\text { explain via SEBUS } \\
\text { effects }\end{array}$ & $\begin{array}{l}\text { Potentially } \\
\text { accounted for } \\
\text { if relaxed } \\
\text { perceptual } \\
\text { priors allow } \\
\text { for greater } \\
\text { driving of } \\
\text { belief } \\
\text { dynamics by } \\
\text { sense data }\end{array}$ & $\begin{array}{l}\text { Potentially } \\
\text { sufficiently } \\
\text { accounted for } \\
\text { by REBUS } \\
\text { effects; could } \\
\text { involve SEBUS } \\
\text { effects if } \\
\text { enhanced } \\
\text { resonant } \\
\text { matching from } \\
\text { prior } \\
\text { expectations } \\
\text { facilitates } \\
\text { veridical } \\
\text { inference }\end{array}$ \\
\hline $\begin{array}{l}\text { 'Normal' } \\
\text { imagining } \\
\text { (relative to } \\
\text { sense-coupled } \\
\text { perception) }\end{array}$ & $\begin{array}{l}\text { Multiscale rhythmic } \\
\text { attractors decoupled from } \\
\text { primary modalities }\end{array}$ & $\begin{array}{l}\text { SEBUS at } \\
\text { hierarchically } \\
\text { intermediate and } \\
\text { higher levels }\end{array}$ & $\begin{array}{l}\text { REBUS at } \\
\text { hierarchically } \\
\text { lower levels }\end{array}$ & $\begin{array}{l}\text { Normal } \\
\text { imagination } \\
\text { probably } \\
\text { involves a } \\
\text { combination of } \\
\text { SEBUS and } \\
\text { REBUS effects, } \\
\text { relative to } \\
\text { sense-coupled } \\
\text { perception }\end{array}$ \\
\hline $\begin{array}{l}\text { Vivid and/or } \\
\text { rich (relative to } \\
\text { normal) } \\
\text { imagining }\end{array}$ & $\begin{array}{l}\text { More powerful and/or } \\
\text { complex sense-decoupled } \\
\text { rhythmic attractors }\end{array}$ & $\begin{array}{l}\text { Potentially } \\
\text { accounted for if } \\
\text { increased firing } \\
\text { increases neural } \\
\text { synchrony and/or } \\
\text { the complexity } \\
\text { activation } \\
\text { dynamics }\end{array}$ & $\begin{array}{l}\text { Difficult to } \\
\text { account for via } \\
\text { REBUS effects }\end{array}$ & $\begin{array}{l}\text { Potentially } \\
\text { sufficiently } \\
\text { accounted for } \\
\text { by SEBUS } \\
\text { effects; could } \\
\text { involve REBUS } \\
\text { effects if } \\
\text { relaxation of } \\
\text { beliefs at higher } \\
\text { levels causes } \\
\text { strengthening at } \\
\text { intermediate } \\
\text { and lower levels } \\
\text { of perceptual } \\
\text { synthesis }\end{array}$ \\
\hline
\end{tabular}




\begin{tabular}{|c|c|c|c|c|}
\hline $\begin{array}{l}\text { Fused (relative } \\
\text { to normal) } \\
\text { imagining }\end{array}$ & $\begin{array}{l}\text { Rhythmic attractors that } \\
\text { are so strong as to be } \\
\text { indistinguishable from } \\
\text { sensations, and/or not } \\
\text { sufficiently contextualized } \\
\text { by other enslaving } \\
\text { processes, such as the } \\
\text { coherent orchestration of } \\
\text { patterns of mental } \\
\text { simulation by the H/E-S } \\
\text { system }\end{array}$ & $\begin{array}{l}\text { Potentially } \\
\text { involving SEBUS } \\
\text { effects if } \\
\text { perceptual } \\
\text { vividness/richness } \\
\text { contributes to } \\
\text { both implicit and } \\
\text { explicit beliefs } \\
\text { about the } \\
\text { veridicality of } \\
\text { perceptions }\end{array}$ & $\begin{array}{l}\text { Potentially } \\
\text { involving } \\
\text { REBUS effects } \\
\text { if beliefs are } \\
\text { relaxed with } \\
\text { respect to } \\
\text { mental actions } \\
\text { involved in } \\
\text { contextualizing } \\
\text { (causal) } \\
\text { sequences (e.g. } \\
\text { "reality } \\
\text { monitoring") }\end{array}$ & $\begin{array}{l}\text { Likely involves } \\
\text { both SEBUS and } \\
\text { REBUS effects }\end{array}$ \\
\hline $\begin{array}{l}\text { Self-aware } \\
\text { (relative to } \\
\text { fused) } \\
\text { imagining }\end{array}$ & $\begin{array}{l}\text { Imaginings } \\
\text { contextualized by the } \\
\text { H/E-S and the systems } \\
\text { with which it interacts }\end{array}$ & $\begin{array}{l}\text { Potentially } \\
\text { involving SEBUS } \\
\text { effects if beliefs } \\
\text { involved in self- } \\
\text { modeling become } \\
\text { stronger and } \\
\text { more coherent }\end{array}$ & $\begin{array}{l}\text { Difficult to } \\
\text { account for via } \\
\text { REBUS effects }\end{array}$ & $\begin{array}{l}\text { Potentially } \\
\text { sufficiently } \\
\text { accounted for } \\
\text { by SEBUS } \\
\text { effects; could } \\
\text { involve REBUS } \\
\text { effects if } \\
\text { relaxation of } \\
\text { beliefs results in } \\
\text { prediction } \\
\text { errors that } \\
\text { enhance self- } \\
\text { monitoring } \\
\text { functions, and } \\
\text { potentially via } \\
\text { relaxation of } \\
\text { "defense } \\
\text { mechanisms" }\end{array}$ \\
\hline $\begin{array}{l}\text { 'Normal' } \\
\text { dreaming } \\
\text { (relative to } \\
\text { waking) }\end{array}$ & $\begin{array}{l}\text { Imagining with sensory } \\
\text { isolation and reduced } \\
\text { enslavement by executive } \\
\text { processes }\end{array}$ & $\begin{array}{l}\text { SEBUS at } \\
\text { hierarchically } \\
\text { intermediate } \\
\text { levels }\end{array}$ & $\begin{array}{l}\text { REBUS at } \\
\text { hierarchically } \\
\text { lower and } \\
\text { higher levels }\end{array}$ & $\begin{array}{l}\text { Normal } \\
\text { dreaming } \\
\text { probably } \\
\text { involves a } \\
\text { combination of } \\
\text { SEBUS and } \\
\text { REBUS effects, } \\
\text { relative to } \\
\text { sense-coupled } \\
\text { perception }\end{array}$ \\
\hline $\begin{array}{l}\text { Vivid and/or } \\
\text { rich (relative to } \\
\text { normal) } \\
\text { dreaming }\end{array}$ & $\begin{array}{l}\text { More powerful and/or } \\
\text { complex sensory-isolated } \\
\text { mental simulations }\end{array}$ & $\begin{array}{l}\text { Potentially } \\
\text { accounted for if } \\
\text { increased firing } \\
\text { increases neural } \\
\text { synchrony and/or } \\
\text { the complexity }\end{array}$ & $\begin{array}{l}\text { Difficult to } \\
\text { account for via } \\
\text { REBUS effects }\end{array}$ & $\begin{array}{l}\text { Potentially } \\
\text { sufficiently } \\
\text { accounted for } \\
\text { by SEBUS } \\
\text { effects; could } \\
\text { involve REBUS }\end{array}$ \\
\hline
\end{tabular}




\begin{tabular}{|l|l|l|l|l|}
\hline & & $\begin{array}{l}\text { activation } \\
\text { dynamics }\end{array}$ & & $\begin{array}{l}\text { effects if } \\
\text { relaxation of } \\
\text { beliefs at higher } \\
\text { levels causes } \\
\text { strengthening at } \\
\text { intermediate } \\
\text { and lower levels } \\
\text { of perceptual } \\
\text { synthesis }\end{array}$ \\
\hline $\begin{array}{l}\text { Lucid (relative } \\
\text { to normal) } \\
\text { dreaming }\end{array}$ & $\begin{array}{l}\text { Imaginings with } \\
\text { maintained involvement } \\
\text { of executive processes } \\
\text { that allow for coherent } \\
\text { self-reflection and } \\
\text { consistent goal-oriented } \\
\text { intentional control } \\
\text { hierarchically } \\
\text { higher levels }\end{array}$ & $\begin{array}{l}\text { Difficult to } \\
\text { account for via } \\
\text { REBUS effects }\end{array}$ & $\begin{array}{l}\text { Potentially } \\
\text { sufficiently } \\
\text { accounted for } \\
\text { by SEBUS } \\
\text { effects; could } \\
\text { involve REBUS } \\
\text { effects if } \\
\text { relaxation of } \\
\text { beliefs results in } \\
\text { prediction } \\
\text { errors that } \\
\text { enhance self- } \\
\text { monitoring } \\
\text { functions, and } \\
\text { potentially via } \\
\text { relaxation of } \\
\text { "defense } \\
\text { mechanisms" }\end{array}$ \\
\end{tabular}

Table 2. Kinds of beliefs.

\begin{tabular}{|l|l|l|l|}
\hline Kinds of beliefs & $\begin{array}{l}\text { Computational } \\
\text { correlates of beliefs }\end{array}$ & $\begin{array}{l}\text { Neural correlates of } \\
\text { beliefs }\end{array}$ & $\begin{array}{l}\text { Examples of kinds of } \\
\text { evidence for different } \\
\text { varieties of altered beliefs }\end{array}$ \\
\hline $\begin{array}{l}\text { Unconscious } \\
\text { sensation }\end{array}$ & $\begin{array}{l}\text { A-matrix likelihoods } \\
\text { over lower levels of } \\
\text { perceptual hierarchies }\end{array}$ & $\begin{array}{l}\text { Primary and } \\
\text { secondary sensory } \\
\text { cortices }\end{array}$ & Implicit learning \\
\hline $\begin{array}{l}\text { Conscious perceptual } \\
\text { synthesis }\end{array}$ & $\begin{array}{l}\text { A-matrix likelihoods } \\
\text { over Intermediate } \\
\text { levels of perceptual } \\
\text { hierarchies bound } \\
\text { together into a } \\
\text { multimodal } \\
\text { workspace; }\end{array}$ & $\begin{array}{l}\text { Transmodal } \\
\text { association cortices }\end{array}$ & $\begin{array}{l}\text { Reportable perceptual } \\
\text { paradigms such as binocular } \\
\text { rivalry or illusion } \\
\text { susceptibility }\end{array}$ \\
\hline $\begin{array}{l}\text { Likely sequences of } \\
\text { state-transitions }\end{array}$ & $\begin{array}{l}\text { B-matrix transition } \\
\text { probabilities }\end{array}$ & $\begin{array}{l}\text { Transitions between } \\
\text { attracting states of } \\
\text { PFC ensembles and } \\
\text { associated striatal- } \\
\text { cortical loops; large- }\end{array}$ & $\begin{array}{l}\text { Sequence tracking; planning } \\
\text { capacities; cognitive control } \\
\text { and flexibility }\end{array}$ \\
\hline
\end{tabular}




\begin{tabular}{|c|c|c|c|}
\hline & & $\begin{array}{l}\text { scale orchestration } \\
\text { by the H/E-S }\end{array}$ & \\
\hline Preferred outcomes & $\begin{array}{l}\text { C-matrix policy } \\
\text { selection via flexibly } \\
\text { realized goals }\end{array}$ & $\begin{array}{l}\text { Ventromedial PFC } \\
\text { and associated } \\
\text { striatal-cortical loops }\end{array}$ & $\begin{array}{l}\text { Behavioral economic } \\
\text { paradigms for assessing } \\
\text { patterns of motivated } \\
\text { behavior }\end{array}$ \\
\hline Habitual responses & $\begin{array}{l}\text { E-matrix policy } \\
\text { selection via direct } \\
\text { action-outcome } \\
\text { mappings }\end{array}$ & $\begin{array}{l}\text { Ventrolateral PFC } \\
\text { and associated } \\
\text { striatal-cortical loops }\end{array}$ & $\begin{array}{l}\text { Tasks assessing rates of } \\
\text { discounting for future utility } \\
\text { based on estimated } \\
\text { impulsivity/restraint }\end{array}$ \\
\hline $\begin{array}{l}\text { Likely positioning } \\
\text { within task } \\
\text { environments }\end{array}$ & $\begin{array}{l}\text { D-matrix initializations } \\
\text { within partially- } \\
\text { observable Markov } \\
\text { decision processes }\end{array}$ & $\begin{array}{l}\text { Modal activation } \\
\text { patterns from default } \\
\text { mode network and } \\
\text { its interactions with } \\
\text { task-positive } \\
\text { networks }\end{array}$ & $\begin{array}{l}\text { Individually variable } \\
\text { perceptual priors; operative } \\
\text { schemas }\end{array}$ \\
\hline Conscious access & $\begin{array}{l}\text { Fictive A-matrix states } \\
\text { orchestrated via } \\
\text { sophisticated affective } \\
\text { inference? }\end{array}$ & $\begin{array}{l}\text { H/E-S guided } \\
\text { orchestration of } \\
\text { coherent self- } \\
\text { referential causal } \\
\text { sequences }\end{array}$ & $\begin{array}{l}\text { Sperling paradigms; } \\
\text { metacognitive calibration } \\
\text { tasks }\end{array}$ \\
\hline
\end{tabular}

Table 3. Kinds of belief updating.

\begin{tabular}{|c|c|c|c|c|c|}
\hline $\begin{array}{l}\text { Kinds } \\
\text { of } \\
\text { belief } \\
\text { updati } \\
\text { ng }\end{array}$ & $\begin{array}{l}\text { Mechanisms of belief } \\
\text { updating }\end{array}$ & $\begin{array}{l}\text { Timescal } \\
\text { es of } \\
\text { belief } \\
\text { updating }\end{array}$ & Direct SEBUS effects & $\begin{array}{l}\text { Direct REBUS } \\
\text { effects }\end{array}$ & Comment \\
\hline $\begin{array}{l}\text { Inferen } \\
\text { ce }\end{array}$ & $\begin{array}{l}\text { Neural activity } \\
\text { dynamics }\end{array}$ & $\begin{array}{l}10 \mathrm{~s} \text { to } \\
100 \mathrm{~s} \text { of } \\
\text { msecs }\end{array}$ & $\begin{array}{l}\text { More precise } \\
\text { predictions via } \\
\text { increased activity } \\
\text { levels }\end{array}$ & $\begin{array}{l}\text { Less precise } \\
\text { predictions via } \\
\text { excitation- } \\
\text { induced } \\
\text { desynchronizat } \\
\text { ion }\end{array}$ & $\begin{array}{l}\text { Particular } \\
\text { combinatio } \\
\text { ns of } \\
\text { strengthene } \\
\text { d and/or } \\
\text { relaxed } \\
\text { inferences } \\
\text { will depend } \\
\text { on } \\
\text { substance, } \\
\text { set, setting, } \\
\text { and dose }\end{array}$ \\
\hline $\begin{array}{l}\text { Learnin } \\
\mathrm{g}\end{array}$ & $\begin{array}{l}\text { Synapse } \\
\text { strengthening/weaken } \\
\text { ing; synaptogenesis; } \\
\text { neurogenesis }\end{array}$ & $\begin{array}{l}\text { Minutes } \\
\text { to days }\end{array}$ & $\begin{array}{l}\text { Stronger driving of } \\
\text { neuronal populations } \\
\text { increasing } \\
\text { opportunities for } \\
\text { more enduring } \\
\text { metabolic changes }\end{array}$ & $\begin{array}{l}\text { Potential for } \\
\text { enhanced } \\
\text { learning if } \\
\text { relaxed prior } \\
\text { expectations } \\
\text { are more easily }\end{array}$ & $\begin{array}{l}\text { Looping } \\
\text { effects } \\
\text { within the } \\
\text { cortical } \\
\text { hierarchy } \\
\text { may make } \\
\text { it difficult }\end{array}$ \\
\hline
\end{tabular}




\begin{tabular}{|c|c|c|c|c|c|}
\hline & & & & $\begin{array}{l}\text { modified/updat } \\
\text { ed }\end{array}$ & $\begin{array}{l}\text { to account } \\
\text { for elevated } \\
\text { learning } \\
\text { under } \\
\text { psychedelic } \\
\text { s via either } \\
\text { SEBUS or } \\
\text { REBUS } \\
\text { effects } \\
\end{array}$ \\
\hline $\begin{array}{l}\text { Structu } \\
\text { re } \\
\text { learnin } \\
\mathrm{g}\end{array}$ & $\begin{array}{l}\text { Formation (and re- } \\
\text { formation) of } \\
\text { compositional } \\
\text { representations as } \\
\text { distributed attractors } \\
\text { and/or predictive } \\
\text { graphs in the } \\
\text { hippocampal/entorhin } \\
\text { al system }\end{array}$ & $\begin{array}{l}\text { Days to } \\
\text { weeks }\end{array}$ & $\begin{array}{l}\text { More intensely } \\
\text { experienced beliefs } \\
\text { may be more likely to } \\
\text { result in } \\
\text { accommodation/upda } \\
\text { ting of schemas }\end{array}$ & $\begin{array}{l}\text { Less rigidly } \\
\text { held beliefs } \\
\text { may be more } \\
\text { easily } \\
\text { modified/updat } \\
\text { ed }\end{array}$ & $\begin{array}{l}\text { Exploring } \\
\text { novel areas } \\
\text { of policy } \\
\text { space with } \\
\text { strengthene } \\
\text { d beliefs at } \\
\text { intermediat } \\
\text { e levels of } \\
\text { perceptual } \\
\text { synthesis } \\
\text { may } \\
\text { provide a } \\
\text { situation } \\
\text { where } \\
\text { structure } \\
\text { learning is } \\
\text { maximized }\end{array}$ \\
\hline $\begin{array}{l}\text { Top- } \\
\text { down } \\
\text { attentio } \\
n\end{array}$ & $\begin{array}{l}\text { Context-sensitive } \\
\text { situationally-specific } \\
\text { precision-weighting } \\
\text { of predictions and } \\
\text { prediction errors, } \\
\text { which could take } \\
\text { multiple forms, } \\
\text { ranging from fictive } \\
\text { motor actions in the } \\
\text { stream of } \\
\text { consciousness, to } \\
\text { transient emotional } \\
\text { states, to more } \\
\text { enduring moods }\end{array}$ & $\begin{array}{l}\text { 100s of } \\
\text { msec to } \\
\text { hours }\end{array}$ & $\begin{array}{l}\text { Strengthening of } \\
\text { policies over } \\
\text { attentional selection } \\
\text { may be most } \\
\text { prevalent for low-to- } \\
\text { moderate levels of 5- } \\
\text { HT2a agonism }\end{array}$ & $\begin{array}{l}\text { Relaxation of } \\
\text { policies over } \\
\text { attentional } \\
\text { selection may } \\
\text { be most } \\
\text { prevalent for } \\
\text { moderate-to- } \\
\text { high levels of 5- } \\
\text { HT2a agonism }\end{array}$ & $\begin{array}{l}\text { Flexible } \\
\text { adjustment } \\
\text { of precision } \\
\text { weighting } \\
\text { may have } \\
\text { powerful } \\
\text { contributio } \\
\text { ns to and } \\
\text { from } \\
\text { altered } \\
\text { states of } \\
\text { consciousn } \\
\text { ess }\end{array}$ \\
\hline
\end{tabular}

\section{Psychedelics, psychopathology, and cognitive spectrums}

SEBUS effects may help account for observations of "psychotomimetic" properties for psychedelic phenomenology, for which overly strong priors represent a face-valid model of multiple aspects of schizophrenia (e.g. hallucinations and 
delusions). Yet, REBUS effects may provide a better description of psychosis due to disruption of deep beliefs (Adams et al., 2013), including the integrative properties of self-related processing (Friston et al., 2016; Noel et al., 2017). Carhart-Harris and Friston (2019) note the similarities between their suggested mechanisms for psychedelic states and the excessive prediction-errors that may represent a partial diathesis for autism (Lawson et al., 2014). However, they go on to argue against this connection based on differences between dynamics unfolding on state and trait levels. While considerations of time scales over which relevant psychological phenomena evolve are surely important, it is nonetheless notable that there are clear dissimilarities between psychedelic and autistic phenomenology, as well as similarities with psychotic states.

SEBUS-like processes may be required to reconcile differences between the altered states suggested by strictly REBUS-based models and particular traits of autism. It has been suggested that autism-spectrum disorders may reflect one pole of a cognitive spectrum with schizophrenia on the opposing end (Byars et al., 2014; Crespi \& Dinsdale, 2019). In this domain and others (Table 1), SEBUS/REBUS mechanisms may be important in suggesting which interventions might be most helpful in which circumstances. For example, by attenuating sensory prediction errors and increasing the ability to form high-level inferences - potentially including the kinds underlying different aspects of social cognition (Call \& Tomasello, 2008; Penn et al., 2008; Rabinowitz et al., 2018) - low-to-moderate doses of 5-HT2a agonists could potentially provide a valuable treatment for autism (De Jaegher, 2013; Markram \& Markram, 2010). Further, a purely REBUS-based model would suggest 5-HT2a agonists as beneficial in some cases of psychosis by attenuating overly strong beliefs (Schmidt et al., 1995). Yet a SEBUS-involving model, in contrast, would suggest that classic psychedelics may be strongly contraindicated for anyone at risk for psychosis - with potential exceptions from specific targeted interventions - and would further point to potential benefits from 5-HT2a antagonism for treating psychotic states (Schmidt et al., 1995).

As described above, the study of visual illusions with varying susceptibility thresholds could potentially provide valuable data on these matters. While resistance to visual illusions has been associated with both psychedelics (Pollan, 2018) and schizophrenia (Gupta et al., 2016), this association might be more reliable with respect to autism (Turi et al., 2018). Hypothetically, we might expect schizophrenia to be particularly strongly associated with resistance to illusions at early- or mid-stages if it is of a variety that has overlapping diatheses with autism (Barneveld et al., 2011), or at late stages where breakdown of global integration may be observed (e.g. via NMDAreceptor auto-immunity) (Braun et al., 2016). To the extent that such inter- and intraindividual differences in predictive processing and cognitive spectrums apply, the kind of models described in Figures 3 and 4 could provide valuable means of characterizing these sources of human variation. Thus, we might be able to adjudicate between mechanistic models based on SEBUS, REBUS, or their combination (ALBUS) by 
assessing the extent to which visual illusion thresholds are raised or lowered with 5HT2a agonists, with potentially notable differences across various kinds of minds.

\section{A comment on ketamine}

The algorithmic and functional level details of the REBUS model may more straightforwardly apply to the computational neuropharmacology of dissociative and NMDA-receptor antagonists like ketamine (Li et al., 2018), which may be associated with increased psychological and brain network flexibility (Braun et al., 2016). Ketamine also acts as an agonist at AMPA receptors (Aleksandrova et al., 2017), which could have the effect of increasing the relative gain on prediction errors, relative to predictions. [Note: Different mixtures of REBUS and SEBUS effects may potentially be observed with ketamine, depending on the particular level of belief hierarchies being considered, and perhaps particularly at higher doses (Jansen, 1997; Martial et al., 2019).] This possibility is considered within REBUS, which addresses this issue as follows:

"Ketamine has similarly been shown to have a rapid mood-lifting effect in depression; however, its ability to engender lasting psychological changes does not appear to be equivalent to that of the classic psychedelics. More work is needed to ascertain why this is the case, but one possibility is that (perhaps due to an absence of a significant gradient in the cortical-subcortical N-methyl-D-aspartate receptor profile) ketamine does not subvert hierarchical message passing in quite the same way as psychedelics, and thus the release of (precise) bottom-up influences on sensitized high-level priors -leading to their longterm revision - is less evident with ketamine. Relatedly, ketamine may not engage insight-related processes in the same way as classic psychedelics appear to."

Alternatively, it may be the case that ketamine does subvert hierarchical message passing along the lines of REBUS, and that the greater association of insight with classical psychedelics is due to SEBUS effects. It should be further noted that ketamine is usually administered at lower doses without the kinds of highly designed sets and settings involved with classic psychedelic interventions (Johnson et al., 2019; Krupitsky \& Grinenko, 1997; Li et al., 2018; Pollan, 2018). At the present moment, we simply lack sufficient data to know ketamine's potential, perhaps especially if provided under conditions capable of recapitulating the phenomenology of near death experiences (Jansen, 1997; Martial et al., 2019, 2021). Theoretically, such high-dose ketamine experiences could provide similar states of "surrender" as involved in therapeutic breakthroughs with classic psychedelics (Griffiths et al., 2016), with potentially farreaching consequences (Pyszczynski et al., 2015).

Breaking free of (and via) default modes; creativity and consciousness

Intensification of belief under classic psychedelics could result in overcoming barriers to breaking typical frames and engaging in non-traditional divergent thinking (Carson, 2010; Girn et al., 2020; Kenett et al., 2018a), so allowing novel streams of 
imagination to be considered (DeYoung et al., 2008). This kind of "out of the box" (or frame) creative thinking can be thought of as driving systems into otherwise uncharted territories of inference space. However, such imaginings would involve temporary local increases in prediction error due to their atypicality. While the complexities of hierarchical predictive processing (HPP) during imagination and dreams is beyond the scope of the present discussion-e.g. what are the precise sources of prediction-errors associated with environmentally-decoupled cognition? - we can safely assume that more novel cognitive states are associated with greater uncertainty. However, if a common principle of prediction-error minimization applies across all scales for persisting complex adaptive systems, then in order for such creative cognition to be viable, it must be buffered by other systems capable of acting as temporary free energy reservoirs (Carhart-Harris \& Friston, 2010; Safron, 2020a, 2021a). That is, the generation of prediction errors by some portion of the brain's generative models must be counterbalanced by other systems capable of maintaining themselves despite this free energy accumulation.

The default mode network (DMN) and its roles in imagination (Beaty et al., 2014, 2015, 2018; Hassabis et al., 2014) may provide this kind of creative dynamo. By constituting a source of strong internally-coherent predictions, the DMN may be capable of temporarily absorbing and then releasing free energy via the shaping of perception and driving of action, perhaps especially when coupled to salience networks (Rueter et al., 2018; Safron, 2021a; Zhou et al., 2018). The connectomic properties of the DMN suggest this core network is ideally suited to serve these functions, having both high centrality, and so high potential for integrating information and exerting control (Kenett et al., 2018b). The DMN is further located distally from primary modalities, and is thereby capable of supporting dynamics more decoupled from immediate sensorimotor engagements (Buckner \& Krienen, 2013; Sormaz et al., 2018). Further, the $\mathrm{DMN}$ is likely to support some of the most stable inferences available to embodiedembedded persons, with major nodes contributing to egocentric perspective, integrated memory, and even the foundations of selfhood and intersubjective modeling (Brewer et al., 2013; Hassabis \& Maguire, 2009; Hazlett et al., 2005; Leech \& Sharp, 2014). The existence of integrative self-processes constitutes a strongly explanatory and parsimonious hypothesis regarding correlations between sensory modalities both within and across periods of time; as such, embodied self-models are well-poised to serve as dominant paradigms and "centers of gravity" for other mental phenomena (Davey \& Harrison, 2018; Dennett, 2014; Safron, 2021a). Indeed, iterative estimation of embodied selfhood and its relationships to the world may be what we mean when we talk about phenomenal consciousness as "something that it feels like" to be a system (Safron, 2020a, 2021a; A. Seth, 2021). Further, the ability of the DMN and associated systems to operate decoupled from immediate environmental exchanges would allow consciousness to be shaped according to counterfactual simulations of past, present, 
and future, so allowing self-processes to be expanded and elaborated in numerous ways, including with respect to forms of objectified $3^{\text {rd }}$-person selfhood with metacognitive capacities (Figures 3,4). And if such counterfactual processing abilities are disrupted, extended selfhood of an "egoic" variety may be similarly compromised with potentially substantial implications for clinical conditions and therapeutic outcomes.

While the precise roles of the DMN may be debated, this kind of trading-off of prediction error across neural systems may be involved in not only the unusual imaginings associated with creativity, but also agentic control, which necessarily involves prediction error generation due to the counterfactual status of yet-to-beachieved goals. In this way, every intentional action is inherently creative in bringing desired states into being through holding onto prior expectations as a kind of sustained imagination. This is a clear case in which SEBUS effects are relevant (Figure 4), and would recast the functional significance of (low-to-moderate) levels of 5-HT2a signaling as crucially involving strengthened beliefs for imaginative planning and goal-oriented cognition more generally (Hesp et al., 2020; Safron \& Sheikhbahaee, 2021). It is notable that the 5-HT2a system first evolved as part of a gene-duplication event corresponding to the advent of jawed fishes (Moutkine et al., 2019), suggesting a potential role in hunting behavior and predator-prey arms races. It is further notable that traditional use of psychedelics also involved agonistic scenarios such as preparation for war between tribes (Grof, 1977). Indeed, providing a source of agentic (broadly construed) control may be one of the primary functions of phenomenal (self-)consciousness and neuromodulation involving 5-HT2a receptors, yet this potential insight would be lost if we solely focused on the relaxation of beliefs under psychedelics.

The strengthening of DMN-mediated counterfactual imaginings with psychedelics is consistent with recent work involving lysergic acid diethylamide, in which dynamic causal modelling established increased effective connectivity between posterior portions of the DMN and associated thalamus (Preller et al., 2019). However, psychedelic experience is often associated with decreased activations and reduced functional connectivity from posterior regions of the DMN (Carhart-Harris et al., 2014; Smigielski et al., 2019). This may seem to contradict the model of imagination-driven creativity described above, yet these findings could potentially be reconciled if particular details of subjective experience depend on these core systems coupling with various sensory hierarchies (Figure 2). Speculatively, increased DMN-internal effective connectivity could enhance capacities for vividly simulating counterfactual possibilities (Figures 3, 4). However, due to this unusually strongly decoupled mode of operation, imaginings could involve a disruption of typical frames, including those established by internal working models of self and world. In this way, both SEBUS and REBUS effects may be observed in various ways at different levels of organization, including intermediate levels of hierarchical abstraction for which conscious experience may be 
realized as a stream of sensorimotor predictions (Prinz, 2017; Safron, 2020a, 2021a, 2021b). However, even if SEBUS effects may be required for explaining some aspects of psychedelic phenomenology, REBUS models may be essential for capturing other aspects of personal experience and clinically relevant outcomes (Tables 4, 5), such as the increased open-mindedness associated with psychedelic-use (Erritzoe et al., 2019; MacLean et al., 2011). In this way, an adequate account of the ways in which psychedelics alter brain and mind likely needs to be expanded into an ALBUS framework capable of integrating across both REBUS and SEBUS phenomena.

\section{Alpha rhythms, ego dissolution, and varieties of conscious experiences}

Regardless of whether belief dynamics are driven by SEBUS or REBUS effects, or their various combinations (ALBUS), associations between psychedelic experience and reduced alpha-band power is notable (Carhart-Harris \& Friston, 2019). While beta oscillations have been associated with "ignition" events in global workspace models (Dehaene \& Changeux, 2011), and are associated with implicit Bayesian beliefs in hierarchical predictive processing, phenomenal consciousness may require the spatial extent of alpha synchronization to achieve organization into coherent egocentric reference frames (Figures 2, 3, and 4) (Safron, 2020a, 2021b). Alpha rhythms have been associated with working memory (Kerr et al., 2013; Michalareas et al., 2016; Palva \& Palva, 2011; Sato et al., 2018), as well as resting wakefulness (or consciousness) more generally, including the paradoxical consciousness observed during REM sleep (Cantero et al., 2002).

These models may seem to oppose common understandings of alpha as indicating "cortical idling", or the resting state of cortex when no longer driven to process information by task demands. Models of the spontaneous emergence of alpha as default synchronizing rhythm of cortex were even suggested by Norbert Wiener (Strogatz, 1994), and since then have been modelled in numerous ways, including within the hierarchical predictive processing paradigm (Alamia \& VanRullen, 2019; Palacios et al., 2019). While seemingly incompatible with alpha oscillations having a central role in consciousness, if these rhythms correspond to the default frequency of updating the sensorium as a (self-centered) conscious controller of action, then we might expect cortex to be tuned to produce coherent synchrony at precisely these frequencies.

Alpha increases observed when subjects close their eyes may be interpreted as contradicting this account of these neural rhythms as having important integrative roles, but rather indicating a return to a default state of "cortical idling" (Erickson et al., 2019). However, this interpretation rests on a bizarre quasi-behaviorist assumption that mental states are reducible to experimental contingencies, rather than being endogenous properties of autonomous systems, such as persons. That is, a task-negative default process being essential for normative functioning is only surprising if we ignore 
that individuals actually have minds whose primary functions are pursuing valued goals as beings in the world, and where resting individuals may likely be engaging in mnemonic and imaginative acts in the service of these tasks of life. For conscious beings, an eyes-closed state would often be one in which visual perception is driven top-down by imagination, as opposed to bottom-up sensations (Deco et al., 2019; Dohmatob et al., 2020; Mediano et al., 2020). Interpretations of alpha rhythms as lacking in functional significance likely involves a similar bizarre reasoning as when neuroscientists were surprised to discover that brains are active when participants are resting quietly in a scanner. Indeed, deflationary accounts of alpha and resting state activity may not only result from (and contribute to) similar conceptual frames of individuals as passive stimulus-response machines, but may speak to inappropriately reductive (and dehumanizing) framings of the same phenomena: the generation of consciousness by experiencing selves.

As described above, and with relevance to consciousness, the default mode network (DMN) is increasingly recognized as the basis for imagination of counterfactual possibilities, "mental time travel", minimal selfhood, and theory of mind (Davey \& Harrison, 2018; Graziano, 2013, 2019; Hassabis et al., 2014; Hassabis \& Maguire, 2009). Indeed, this core network is a major source of alpha synchronization (Jann et al., 2009; Knyazev et al., 2011). It is also notable that downregulation of posterior DMN regions has been observed with both psychedelic and meditative experiences (Brewer et al., 2011, 2013; Li et al., 2018; Smigielski et al., 2019), both of which are associated with (hopefully temporary) "ego disintegration" (Deane et al., 2020). That is, we might expect that disruptions of systems underlying coherent egocentric reference frames to be highly impactful (Safron, 2020a, 2021a, 2021b), potentially contributing to alterations of egoic selfhood, for both better and worse (Ciaunica et al., 2021; M. Johnson et al., 2008).

A potential challenge to these models of DMN/alpha as central for coherent conscious processing is that psychedelic and meditative experiences are often discussed as involving "elevated consciousness." Some $3^{\text {rd }}$-person supporting evidence for elevated consciousness level under psychedelics includes evidence of increased neural complexity and tuning towards criticality (Atasoy et al., 2018; Carhart-Harris, 2018), with potentially similar interpretations for greater effective connectivity between posterior medial cortices and associated thalamus (Preller et al., 2019). Yet even if alpha rhythms are severely disrupted, coherent, metastable (beta-band) synchronous complexes could still form along subnetworks enabling conscious experience, albeit of an unusual variety due to atypical integration (Figures 3, 4). However, if this disruption results in reduced suppression via descending predictions, then failures to "explainaway" ascending observations could result in more information entering conscious awareness (Figures 1, 2). In the case of imaginings (Figure 3), disrupted predictions could result in deeper portions of the generative model 'surprising itself' via looping 
effects, potentially even further increasing the gain on processes associated with modulating consciousness levels via general arousal. In brief, the psychedelic state could involve elevated consciousness, but with expanded rhythmic complexes involving dynamics of a more entropic (or super-critical) variety (Carhart-Harris, 2018; Carhart-Harris et al., 2014). To draw an analogy, the light of consciousness under such altered conditions could be more like a "lantern" kaleidoscope than a focused laser: good at generating intense and colorful fractals, but not as good for pointing at specific things, yet potentially adaptive in promoting cognitive exploration 4/17/2023 2:51:00 AM.

\section{Conclusions}

While SEBUS and REBUS effects may converge with moderate-to-high levels of 5-HT2a agonism, we might expect qualitatively different effects with low-to-moderate doses. Under regimes characteristic of micro-dosing or threshold experiences (Figures 3, 4), consciousness may be elevated without substantially altering normative belief dynamics. In these ways, micro-dosing may provide a promising and overlooked therapeutic intervention for depression (e.g. anhedonia), autism, Alzheimer's disease, and disorders of consciousness. In contrast to a purely REBUS model, a SEBUSinvolving ALBUS model makes different predictions for the potential utility of various psychedelic interventions for these debilitating conditions, for which advances in treatment could have impacts on public health that may be difficult to overstate.

In Tables 4 and 5 we begin to explore ways in which SEBUS- and REBUSinvolving models suggest different therapeutic use cases and explanations for psychedelic phenomena. While informed by commonly reported effects from psychedelic interventions as well as theoretical considerations, these suggestions should all be understood as extremely tentative, with a systematic research program being required for either their verification or falsification. Given the immense potential of 5HT2a agonists - and perhaps also NMDA receptor antagonists - for both clinical and basic science, we believe substantial further work (and funding) is warranted to explore the conditions under which we might expect both relaxed, strengthened, and more generally altered beliefs under psychedelics and other varieties of conscious experiences. 


\section{Acknowledgements}

I would like to thank Robin Carhart-Harris for his foundational work which helped to inspire this synthesis, Karl Friston for his mentorship and feedback on earlier incarnations of these ideas (and for providing the framework that structures most of my thinking), Matthew Johnson for his feedback on a previous version of this manuscript. I would also like to thank members of the Center for Psychedelic and Consciousness Research at Johns Hopkins University School of Medicine for their stimulating conversations and support. Finally, I would like to thank Victoria Klimaj for helping to make the figures which form the heart of these models of different kinds of minds. 
Table 4: Suggested use cases for psychedelics as therapies under different mechanistic models, with SEBUS effects hypothesized to predominate with microdosing, and a combination of SEBUS and REBUS effects with macrodosing. Please note: this table is neither meant to be exhaustive nor definitive.

\begin{tabular}{|c|c|c|c|}
\hline & SEBUS effects & REBUS effects & $\begin{array}{l}\text { ALBUS (powerfully altering } \\
\text { internal working models) }\end{array}$ \\
\hline Depression & $\begin{array}{l}\text { Behavioral activation; } \\
\text { increased ability to imagine } \\
\text { and experience positive } \\
\text { outcomes }\end{array}$ & $\begin{array}{l}\text { Interrupting } \\
\text { depressogenic } \\
\text { patterns of cognition } \\
\text { and behavior (e.g. } \\
\text { rumination) }\end{array}$ & $\begin{array}{l}\text { Microdosing for behavioral } \\
\text { activation } \\
\text { Macrodosing for cognitive } \\
\text { restructuring }\end{array}$ \\
\hline Anxiety & $\begin{array}{l}\text { Potential improvements } \\
\text { through increased confidence, } \\
\text { but possibly maladaptive } \\
\text { effects due to greater } \\
\text { vividness of negative } \\
\text { imaginings }\end{array}$ & $\begin{array}{l}\text { Reducing the grip of } \\
\text { anxiety-provoking } \\
\text { beliefs }\end{array}$ & $\begin{array}{l}\text { Microdosing for increasing } \\
\text { confidence, and possibly as an } \\
\text { adjunct to exposure } \\
\text { interventions } \\
\text { Macrodosing for flooding and } \\
\text { reconsolidation }\end{array}$ \\
\hline Creativity & $\begin{array}{l}\text { Both divergent and } \\
\text { convergent creativity } \\
\text { potentially elevated through } \\
\text { enhanced associations and } \\
\text { cognitive control }\end{array}$ & $\begin{array}{l}\text { More divergent } \\
\text { creativity through } \\
\text { freer associations }\end{array}$ & $\begin{array}{l}\text { Microdosing for either } \\
\text { convergent or divergent } \\
\text { creativity } \\
\text { Macrodosing for divergent } \\
\text { creativity }\end{array}$ \\
\hline Autism spectrum & $\begin{array}{l}\text { Potentially beneficial through } \\
\text { reducing the gain on } \\
\text { excessive prediction error and } \\
\text { increasing the gain on central } \\
\text { integration, but possibly } \\
\text { contraindicated if } \\
\text { accompanied by tendencies } \\
\text { towards anxiety }\end{array}$ & $\begin{array}{l}\text { Potentially beneficial } \\
\text { for reducing overly } \\
\text { rigid patterns and } \\
\text { increasing cognitive } \\
\text { flexibility, and } \\
\text { potentially insight }\end{array}$ & $\begin{array}{l}\text { Microdosing for enhanced } \\
\text { empathy and attenuated } \\
\text { sensory sensitivity } \\
\text { Macrodosing for breaking } \\
\text { free of rigid patterns and } \\
\text { promoting self/other } \\
\text { awareness and insight }\end{array}$ \\
\hline Schizophrenia spectrum & $\begin{array}{l}\text { Likely contraindicated, unless } \\
\text { condition is driven by } \\
\text { functional disconnection, in } \\
\text { which case some } \\
\text { strengthening of beliefs could } \\
\text { potentially be beneficial }\end{array}$ & $\begin{array}{l}\text { Potentially desirable } \\
\text { for reducing some } \\
\text { forms of delusions } \\
\text { based on self- } \\
\text { reinforcing beliefs; } \\
\text { contraindicated if } \\
\text { condition is driven } \\
\text { by functional } \\
\text { disconnection }\end{array}$ & $\begin{array}{l}\text { Microdosing for enhancing } \\
\text { executive functions } \\
\text { Macrodosing as last-line } \\
\text { intervention; possible } \\
\text { protective effects for } \\
\text { prodrome through enhancing } \\
\text { integration, and possibly } \\
\text { inoculation with respect to } \\
\text { epistemic hygiene }\end{array}$ \\
\hline Traumatic brain injury & $\begin{array}{l}\text { Potentially protective by } \\
\text { encouraging sustained } \\
\text { cognitive engagement, } \\
\text { preventing learned non-use, } \\
\text { and promoting } \\
\text { neuroplasticity }\end{array}$ & $\begin{array}{l}\text { Potentially useful for } \\
\text { processing distress } \\
\text { and potentially } \\
\text { maladaptive } \\
\text { cognition and } \\
\text { behavior patterns } \\
\text { (e.g. cognitive }\end{array}$ & $\begin{array}{l}\text { Microdosing for aiding } \\
\text { recovery } \\
\text { Macrodosing for breaking } \\
\text { through maladaptive patterns } \\
\text { to make room for new ones; } \\
\text { may also be most beneficial }\end{array}$ \\
\hline
\end{tabular}




\begin{tabular}{|c|c|c|c|}
\hline & & $\begin{array}{l}\text { avoidance, activity } \\
\text { avoidance) }\end{array}$ & $\begin{array}{l}\text { for opening plasticity } \\
\text { windows }\end{array}$ \\
\hline Cognitive decline & $\begin{array}{l}\text { Potentially beneficial for } \\
\text { similar reasons to those } \\
\text { described for traumatic brain } \\
\text { injury }\end{array}$ & $\begin{array}{l}\text { Potentially beneficial } \\
\text { for similar reasons to } \\
\text { those described for } \\
\text { traumatic brain } \\
\text { injury }\end{array}$ & $\begin{array}{l}\text { Microdosing for prevention } \\
\text { Macrodosing for condition } \\
\text { management (and possibly } \\
\text { prevention if avoidance } \\
\text { contributes to cognitive } \\
\text { reserve depletion) }\end{array}$ \\
\hline Wakefulness disorders & $\begin{array}{l}\text { Potentially highly beneficial } \\
\text { by increasing consciousness } \\
\text { level }\end{array}$ & $\begin{array}{l}\text { Potentially beneficial } \\
\text { if relaxed beliefs } \\
\text { indirectly produce } \\
\text { arousal through } \\
\text { increased prediction- } \\
\text { error }\end{array}$ & $\begin{array}{l}\text { Microdosing for conditions } \\
\text { such as narcolepsy } \\
\text { Macrodosing as potentially } \\
\text { beneficial for coma and } \\
\text { persistent vegetative states }\end{array}$ \\
\hline Addiction & $\begin{array}{l}\text { Potentially contraindicated, } \\
\text { unless microdosing provides } \\
\text { effective substitution for more } \\
\text { addictive substances; } \\
\text { increased abilities to visualize } \\
\text { consequences/goals and } \\
\text { potentially greater } \\
\text { connections to values could } \\
\text { aid in resisting overly steep } \\
\text { discounting of future utility }\end{array}$ & $\begin{array}{l}\text { Potentially beneficial } \\
\text { by weakening overly- } \\
\text { strong self- } \\
\text { reinforcing memories }\end{array}$ & $\begin{array}{l}\text { Microdosing as potential } \\
\text { substitute for stimulants } \\
\text { Macrodosing as potentially } \\
\text { beneficial for all addictions }\end{array}$ \\
\hline Personality disorders & $\begin{array}{l}\text { Likely contraindicated as a } \\
\text { standalone treatment, but } \\
\text { potentially beneficial in } \\
\text { conjunction with } \\
\text { psychotherapy }\end{array}$ & $\begin{array}{l}\text { Potentially beneficial } \\
\text { via insight, unless } \\
\text { psychedelic } \\
\text { experiences promote } \\
\text { spiritual bypassing or } \\
\text { destabilize already } \\
\text { weakened self- } \\
\text { processes }\end{array}$ & $\begin{array}{l}\text { Microdosing as adjunct to } \\
\text { psychotherapy } \\
\text { Macrodosing for updating } \\
\text { maladaptive internal working } \\
\text { models; potentially more } \\
\text { effective with guided sessions }\end{array}$ \\
\hline $\begin{array}{l}\text { Post-Traumatic Stress } \\
\text { Disorder }\end{array}$ & $\begin{array}{l}\text { Potentially contraindicated } \\
\text { outside of exposure therapies } \\
\text { due to risk of enhancing } \\
\text { traumatic imaginings } \\
\text { Possibly beneficial if other } \\
\text { beliefs are allowed to more } \\
\text { effectively compete with } \\
\text { dominance from traumatizing } \\
\text { models }\end{array}$ & $\begin{array}{l}\text { Potentially beneficial } \\
\text { by weakening overly- } \\
\text { strong self- } \\
\text { reinforcing memories }\end{array}$ & $\begin{array}{l}\text { Microdosing as adjunct for } \\
\text { gradual exposure therapies } \\
\text { Macrodosing for flooding and } \\
\text { compassion-based protocols }\end{array}$ \\
\hline Chronic pain & $\begin{array}{l}\text { Likely highly variable across } \\
\text { individuals, with some } \\
\text { experiencing undesirable } \\
\text { strengthening of pain- } \\
\text { enhancing patterns of } \\
\text { cognition, and others } \\
\text { experiencing potentially } \\
\text { beneficial reward-related } \\
\text { analgesia (above and beyond } \\
\text { anti-inflammatory properties }\end{array}$ & $\begin{array}{l}\text { Potentially beneficial } \\
\text { for disrupting self- } \\
\text { reinforcing patterns } \\
\text { of pain-enhancing } \\
\text { cognition; possibly } \\
\text { temporarily harmful } \\
\text { if reduced gating of } \\
\text { prediction-errors } \\
\text { exacerbates pain } \\
\text { sensations }\end{array}$ & $\begin{array}{l}\text { Microdosing for reward- } \\
\text { related analgesia and anti- } \\
\text { inflammatory effects } \\
\text { Macrodosing for enhancing } \\
\text { self-compassion and } \\
\text { acceptance }\end{array}$ \\
\hline
\end{tabular}




\begin{tabular}{|c|c|c|c|}
\hline & $\begin{array}{l}\text { associated with 5-HT2a } \\
\text { receptors); possibly effective } \\
\text { as adjunct to hypnosis-based } \\
\text { interventions }\end{array}$ & & \\
\hline Terminal illness & $\begin{array}{l}\text { Potentially helpful by } \\
\text { strengthening access to } \\
\text { sources of meaning from core } \\
\text { values and transpersonal } \\
\text { connection }\end{array}$ & $\begin{array}{l}\text { Potentially beneficial } \\
\text { by weakening } \\
\text { schemas involving } \\
\text { death anxiety }\end{array}$ & $\begin{array}{l}\text { Microdosing for increased } \\
\text { engagement with life } \\
\text { Macrodosing for greater } \\
\text { acceptance, connecting to } \\
\text { higher meanings, and } \\
\text { potentially beneficial (and } \\
\text { possibly transcendent) } \\
\text { changes in world view }\end{array}$ \\
\hline Existential anxiety & $\begin{array}{l}\text { Potentially helpful for similar } \\
\text { reasons to those involved in } \\
\text { overcoming distress from } \\
\text { terminal illness }\end{array}$ & $\begin{array}{l}\text { Potentially beneficial } \\
\text { if connections to } \\
\text { meaning are actively } \\
\text { blocked by pre- } \\
\text { existing schemas }\end{array}$ & $\begin{array}{l}\text { Microdosing for greater sense } \\
\text { of agency, engagement with } \\
\text { life, and connection to } \\
\text { meanings } \\
\text { Macrodosing as potentially } \\
\text { beneficial for similar reasons } \\
\text { to those involved with } \\
\text { terminal illness }\end{array}$ \\
\hline
\end{tabular}


Table 5: Potential accounts of psychedelic phenomena under different mechanistic models. SEBUS and REBUS columns indicate respectively strengthened and relaxed beliefs, potentially primarily observed with respectively low-to-moderate and moderate-to-high levels of 5-HT2a agonism. ALBUS indicates a mixture of both SEBUS and REBUS effects, with potentially highly variable combinations as a function of set, setting, and substance/dosing. Please note: this table is neither meant to be exhaustive nor definitive.

\begin{tabular}{|c|c|c|c|}
\hline & SEBUS & REBUS & ALBUS \\
\hline Hallucinations & $\begin{array}{l}\text { Anomalous } \\
\text { perceptual inference } \\
\text { from overly-strong } \\
\text { priors }\end{array}$ & $\begin{array}{l}\text { Anomalous perceptual } \\
\text { inference from breakdown of } \\
\text { integration by deep beliefs, } \\
\text { possibly involving indirect } \\
\text { strengthening of lower } \\
\text { hierarchical levels }\end{array}$ & $\begin{array}{l}\text { Different combinations of } \\
\text { SEBUS and REBUS effects } \\
\text { would be more-or-less } \\
\text { explanatory based on the } \\
\text { specific type of hallucinations } \\
\text { being considered }\end{array}$ \\
\hline Fractal imagery & $\begin{array}{l}\text { Revealing useful } \\
\text { priors derived from } \\
\text { experience, and } \\
\text { possibly evolution }\end{array}$ & $\begin{array}{l}\text { Driving of perception by } \\
\text { bottom-up prediction errors } \\
\text { reflecting the fractal structure of } \\
\text { the world }\end{array}$ & $\begin{array}{l}\text { Increased shaping of } \\
\text { perception by low-level priors } \\
\text { (SEBUS), potentially with less } \\
\text { competition from high-level } \\
\text { expectations (REBUS) }\end{array}$ \\
\hline Synesthesia & $\begin{array}{l}\text { Increased cross- } \\
\text { modal priors }\end{array}$ & $\begin{array}{l}\text { Anarchic cross-modal signaling } \\
\text { due to disorganized central } \\
\text { integration }\end{array}$ & $\begin{array}{l}\text { Possibly clearest account, since } \\
\text { cross-modal priors would not } \\
\text { necessarily be synesthetic with } \\
\text { only strengthened beliefs } \\
\text { (SEBUS), and novel modes of } \\
\text { perceptual synthesis could be } \\
\text { obstructed with only relaxed } \\
\text { beliefs (REBUS) }\end{array}$ \\
\hline Entity encounters & $\begin{array}{l}\text { Strengthened } \\
\text { evolutionary and } \\
\text { developmental } \\
\text { agency priors }\end{array}$ & $\begin{array}{l}\text { Anomalous agency attributions } \\
\text { due to breakdown of self- } \\
\text { processes }\end{array}$ & $\begin{array}{l}\text { Combination of relaxed self- } \\
\text { models (REBUS) and } \\
\text { strengthened agent-perception } \\
\text { priors (SEBUS), potentially } \\
\text { also involving anomalous } \\
\text { inference from incoherently } \\
\text { integrated efference copies }\end{array}$ \\
\hline $\begin{array}{l}\text { Feelings of } \\
\text { timelessness }\end{array}$ & $\begin{array}{l}\text { Crowding out of } \\
\text { temporally-extended } \\
\text { self-processes by } \\
\text { experiential } \\
\text { absorption }\end{array}$ & $\begin{array}{l}\text { Relaxing of beliefs related to } \\
\text { internal working models of self } \\
\text { and world resulting in less } \\
\text { engagement with temporally } \\
\text { deep and counterfactually rich } \\
\text { processing }\end{array}$ & $\begin{array}{l}\text { Conjunction of less elaborative } \\
\text { self-modeling (REBUS) and } \\
\text { enhanced capacities for } \\
\text { absorption (SEBUS and } \\
\text { REBUS) }\end{array}$ \\
\hline $\begin{array}{l}\text { Feelings of unity and } \\
\text { deep order }\end{array}$ & $\begin{array}{l}\text { Strengthening of core } \\
\text { socioemotional } \\
\text { priors from early } \\
\text { developmental } \\
\text { stages }\end{array}$ & $\begin{array}{l}\text { Reduced modeling of self as } \\
\text { separate from world }\end{array}$ & $\begin{array}{l}\text { Conjunction of reduced } \\
\text { objectified selfhood (REBUS } \\
\text { and SEBUS-via-absorption) } \\
\text { and enhanced core priors for } \\
\text { connection (SEBUS) }\end{array}$ \\
\hline Recovered memories & $\begin{array}{l}\text { Increased conscious } \\
\text { access }\end{array}$ & $\begin{array}{l}\text { Reduced suppression from } \\
\text { defense mechanisms (e.g. } \\
\text { experiential avoidance patterns) }\end{array}$ & $\begin{array}{l}\text { Potential for recovering } \\
\text { memories that are either weak } \\
\text { (SEBUS) or blocked by defense } \\
\text { mechanisms (REBUS) }\end{array}$ \\
\hline
\end{tabular}




\begin{tabular}{|c|c|c|c|}
\hline False memories & Misleading vividness & Reduced reality monitoring & $\begin{array}{l}\text { High probability of false } \\
\text { memories through } \\
\text { combination of reduced meta- } \\
\text { cognition (REBUS) and } \\
\text { enhanced perception (SEBUS) }\end{array}$ \\
\hline $\begin{array}{l}\text { Personal } \\
\text { transformation }\end{array}$ & $\begin{array}{l}\text { Increased perceptual } \\
\text { and imaginative } \\
\text { abilities enhancing } \\
\text { capacity for } \\
\text { visualizing desired } \\
\text { goals and undesired } \\
\text { consequences of } \\
\text { behavior patterns }\end{array}$ & $\begin{array}{l}\text { Letting go of rigid beliefs via } \\
\text { relaxation of internal working } \\
\text { models }\end{array}$ & $\begin{array}{l}\text { Greatest opportunities for } \\
\text { change by allowing new } \\
\text { patterns (REBUS) to be } \\
\text { explored with high } \\
\text { experiential intensity (SEBUS) }\end{array}$ \\
\hline Dissociation & $\begin{array}{l}\text { Indirect consequence } \\
\text { of fusion with } \\
\text { experience }\end{array}$ & $\begin{array}{l}\text { Relaxation of core beliefs related } \\
\text { to selfhood }\end{array}$ & $\begin{array}{l}\text { Different combinations of } \\
\text { SEBUS and REBUS effects } \\
\text { could contribute to different } \\
\text { kinds of dissociative } \\
\text { experiences in highly variable } \\
\text { ways }\end{array}$ \\
\hline Ego death & $\begin{array}{l}\text { Potential } \\
\text { consequence of } \\
\text { extreme absorption } \\
\text { causing a collapse of } \\
\text { temporally-deep and } \\
\text { counterfactually-rich } \\
\text { modeling by which } \\
\text { extended selfhood is } \\
\text { actively } \\
\text { inferred/constructed }\end{array}$ & $\begin{array}{l}\text { Extreme relaxation of core } \\
\text { beliefs related to both extended } \\
\text { and embodied selfhood }\end{array}$ & $\begin{array}{l}\text { Ego-death-related self- } \\
\text { restructuring from intensely } \\
\text { experienced (SEBUS) } \\
\text { selfless/non-dual experiences } \\
\text { (REBUS and possibly SEBUS } \\
\text { via extreme absorption) }\end{array}$ \\
\hline Ontological shock & $\begin{array}{l}\text { Strong experiences } \\
\text { causing extreme } \\
\text { updating of core } \\
\text { (and potentially } \\
\text { stabilizing) beliefs } \\
\text { (REBUS effects via } \\
\text { SEBUS effects) }\end{array}$ & $\begin{array}{l}\text { Difficulty integrating } \\
\text { experiences not structured } \\
\text { according to internal working } \\
\text { models of self and world }\end{array}$ & $\begin{array}{l}\text { Similar explanation as for ego } \\
\text { death in terms of combining } \\
\text { intense experiences (SEBUS) } \\
\text { outside of normal modes of } \\
\text { sense-making (REBUS) }\end{array}$ \\
\hline $\begin{array}{l}\text { Delusional (but } \\
\text { potentially generative } \\
\text { with respect to } \\
\text { creativity) cognition }\end{array}$ & $\begin{array}{l}\text { Misleading vividness } \\
\text { resulting in poorly- } \\
\text { evidenced models } \\
\text { becoming resistant to } \\
\text { updating/falsification }\end{array}$ & $\begin{array}{l}\text { Relaxation of beliefs relating to } \\
\text { active reality monitoring and } \\
\text { epistemic hygiene }\end{array}$ & $\begin{array}{l}\text { Kindling delusions (and some } \\
\text { forms of creativity) by } \\
\text { combining relaxed prior } \\
\text { models (REBUS) with } \\
\text { strengthened novel } \\
\text { information (SEBUS) }\end{array}$ \\
\hline $\begin{array}{l}\text { Conversion } \\
\text { experiences (e.g. } \\
\text { adopting new } \\
\text { religions, altered } \\
\text { political affiliations) }\end{array}$ & $\begin{array}{l}\text { Intense experience of } \\
\text { an alternative reality } \\
\text { provided by } \\
\text { set/setting }\end{array}$ & $\begin{array}{l}\text { Making core beliefs subject to } \\
\text { updating/falsification via } \\
\text { relaxation }\end{array}$ & $\begin{array}{l}\text { Radical transformation of } \\
\text { overarching narratives with } \\
\text { respect to self/world by } \\
\text { combining relaxed core beliefs } \\
\text { (REBUS) with strengthened } \\
\text { suggested beliefs (SEBUS) }\end{array}$ \\
\hline Personality change & $\begin{array}{l}\text { Increased ability to } \\
\text { perceive and pursue } \\
\text { new goals }\end{array}$ & $\begin{array}{l}\text { Relaxation of internal working } \\
\text { models creating a space within } \\
\text { which new characteristic } \\
\text { adaptations may form }\end{array}$ & $\begin{array}{l}\text { Exploring and being updated } \\
\text { by intensely experienced } \\
\text { (SEBUS) alternative ways of } \\
\text { being (REBUS) }\end{array}$ \\
\hline
\end{tabular}




\section{References}

Adams, R. A., Pinotsis, D., Tsirlis, K., Unruh, L., Mahajan, A., Horas, A. M., Convertino, L., Summerfelt, A., Sampath, H., Du, X. M., Kochunov, P., Ji, J. L., Repovs, G., Murray, J. D., Friston, K. J., Hong, L. E., \& Anticevic, A. (2022). Computational Modeling of Electroencephalography and Functional Magnetic Resonance Imaging Paradigms Indicates a Consistent Loss of Pyramidal Cell Synaptic Gain in Schizophrenia. Biological Psychiatry, 91(2), 202-215.

https://doi.org/10.1016/j.biopsych.2021.07.024

Adams, R. A., Stephan, K. E., Brown, H. R., Frith, C. D., \& Friston, K. J. (2013). The computational anatomy of psychosis. Frontiers in Psychiatry, 4, 47. https://doi.org/10.3389/fpsyt.2013.00047

Ahmad, S., \& Scheinkman, L. (2019). How Can We Be So Dense? The Benefits of Using Highly Sparse Representations. ArXiv Preprint ArXiv:1903.11257.

Alamia, A., \& VanRullen, R. (2019). Alpha oscillations and traveling waves: Signatures of predictive coding? PLOS Biology, 17(10), e3000487. https://doi.org/10.1371/journal.pbio.3000487

Aleksandrova, L. R., Phillips, A. G., \& Wang, Y. T. (2017). Antidepressant effects of ketamine and the roles of AMPA glutamate receptors and other mechanisms beyond NMDA receptor antagonism. Journal of Psychiatry $\mathcal{E}$ Neuroscience : JPN, 42(4), 222-229. https://doi.org/10.1503/jpn.160175

Anderson, P. W. (1972). More Is Different. Science, 177(4047), 393-396. https://doi.org/10.1126/science.177.4047.393

Aru, J., Suzuki, M., \& Larkum, M. E. (2020). Cellular Mechanisms of Conscious Processing. Trends in Cognitive Sciences, 24(10), 814-825.

https://doi.org/10.1016/j.tics.2020.07.006

Aru, J., Suzuki, M., Rutiku, R., Larkum, M. E., \& Bachmann, T. (2019). Coupling the State and Contents of Consciousness. Frontiers in Systems Neuroscience, 13. https://doi.org/10.3389/fnsys.2019.00043

Atasoy, S., Deco, G., \& Kringelbach, M. L. (2019). Playing at the Edge of Criticality: Expanded Whole-Brain Repertoire of Connectome-Harmonics. In N. Tomen, J. M. Herrmann, \& U. Ernst (Eds.), The Functional Role of Critical Dynamics in Neural Systems (pp. 27-45). Springer International Publishing. https://doi.org/10.1007/978-3-030-20965-0_2

Atasoy, S., Deco, G., Kringelbach, M. L., \& Pearson, J. (2018). Harmonic Brain Modes: A Unifying Framework for Linking Space and Time in Brain Dynamics. The Neuroscientist: A Review Journal Bringing Neurobiology, Neurology and Psychiatry, 24(3), 277-293. https://doi.org/10.1177/1073858417728032

Barneveld, P. S., Pieterse, J., de Sonneville, L., van Rijn, S., Lahuis, B., van Engeland, H., \& Swaab, H. (2011). Overlap of autistic and schizotypal traits in adolescents with 
Autism Spectrum Disorders. Schizophrenia Research, 126(1-3), 231-236.

https://doi.org/10.1016/j.schres.2010.09.004

Barrett, F. S., Johnson, M. W., \& Griffiths, R. R. (2015). Validation of the revised Mystical

Experience Questionnaire in experimental sessions with psilocybin. Journal of Psychopharmacology (Oxford, England), 29(11), 1182-1190.

https://doi.org/10.1177/0269881115609019

Barsalou, L. W. (2010). Grounded cognition: Past, present, and future. Topics in Cognitive Science, 2(4), 716-724. https://doi.org/10.1111/j.1756-8765.2010.01115.x

Bastos, A. M., Usrey, W. M., Adams, R. A., Mangun, G. R., Fries, P., \& Friston, K. J. (2012). Canonical microcircuits for predictive coding. Neuron, 76(4), 695-711. https://doi.org/10.1016/j.neuron.2012.10.038

Beaty, R. E., Benedek, M., Barry Kaufman, S., \& Silvia, P. J. (2015). Default and Executive Network Coupling Supports Creative Idea Production. Scientific Reports, 5, 10964. https://doi.org/10.1038/srep10964

Beaty, R. E., Benedek, M., Wilkins, R. W., Jauk, E., Fink, A., Silvia, P. J., Hodges, D. A., Koschutnig, K., \& Neubauer, A. C. (2014). Creativity and the default network: A functional connectivity analysis of the creative brain at rest. Neuropsychologia, 64, 92-98. https://doi.org/10.1016/j.neuropsychologia.2014.09.019

Beaty, R. E., Kenett, Y. N., Christensen, A. P., Rosenberg, M. D., Benedek, M., Chen, Q., Fink, A., Qiu, J., Kwapil, T. R., Kane, M. J., \& Silvia, P. J. (2018). Robust prediction of individual creative ability from brain functional connectivity. Proceedings of the National Academy of Sciences, 115(5), 1087-1092. https://doi.org/10.1073/pnas.1713532115

Bengio, Y. (2017). The Consciousness Prior. ArXiv:1709.08568 [Cs, Stat]. http://arxiv.org/abs/1709.08568

Braun, U., Schäfer, A., Bassett, D. S., Rausch, F., Schweiger, J. I., Bilek, E., Erk, S., Romanczuk-Seiferth, N., Grimm, O., Geiger, L. S., Haddad, L., Otto, K., Mohnke, S., Heinz, A., Zink, M., Walter, H., Schwarz, E., Meyer-Lindenberg, A., \& Tost, H. (2016). Dynamic brain network reconfiguration as a potential schizophrenia genetic risk mechanism modulated by NMDA receptor function. Proceedings of the National Academy of Sciences, 113(44), 12568-12573.

https://doi.org/10.1073/pnas.1608819113

Brewer, J. A., Garrison, K. A., \& Whitfield-Gabrieli, S. (2013). What about the "Self" is Processed in the Posterior Cingulate Cortex? Frontiers in Human Neuroscience, 7. https://doi.org/10.3389/fnhum.2013.00647

Brewer, J. A., Worhunsky, P. D., Gray, J. R., Tang, Y.-Y., Weber, J., \& Kober, H. (2011). Meditation experience is associated with differences in default mode network activity and connectivity. Proceedings of the National Academy of Sciences. https://doi.org/10.1073/pnas.1112029108 
Brouwer, A., \& Carhart-Harris, R. L. (2020). Pivotal mental states. Journal of Psychopharmacology (Oxford, England), 269881120959637.

https://doi.org/10.1177/0269881120959637

Buchanan, G. F., Smith, H. R., MacAskill, A., \& Richerson, G. B. (2015). 5-HT2A receptor activation is necessary for CO2-induced arousal. Journal of Neurophysiology, 114(1), 233-243. https://doi.org/10.1152/jn.00213.2015

Buckner, R. L., \& Krienen, F. M. (2013). The evolution of distributed association networks in the human brain. Trends in Cognitive Sciences, 17(12), 648-665. https://doi.org/10.1016/j.tics.2013.09.017

Buzsáki, G., \& Watson, B. O. (2012). Brain rhythms and neural syntax: Implications for efficient coding of cognitive content and neuropsychiatric disease. Dialogues in Clinical Neuroscience, 14(4), 345-367.

Byars, S. G., Stearns, S. C., \& Boomsma, J. J. (2014). Opposite risk patterns for autism and schizophrenia are associated with normal variation in birth size: Phenotypic support for hypothesized diametric gene-dosage effects. Proceedings of the Royal Society B: Biological Sciences, 281(1794), 20140604. https://doi.org/10.1098/rspb.2014.0604

Call, J., \& Tomasello, M. (2008). Does the chimpanzee have a theory of mind? 30 years later. Trends in Cognitive Sciences, 12(5), 187-192. https://doi.org/10.1016/j.tics.2008.02.010

Cantero, J. L., Atienza, M., \& Salas, R. M. (2002). Human alpha oscillations in wakefulness, drowsiness period, and REM sleep: Different electroencephalographic phenomena within the alpha band. Neurophysiologie Clinique = Clinical Neurophysiology, 32(1), 54-71. https://doi.org/10.1016/s09877053(01)00289-1

Carhart-Harris, R. L. (2018). The entropic brain-Revisited. Neuropharmacology, 142, 167178. https://doi.org/10.1016/j.neuropharm.2018.03.010

Carhart-Harris, R. L., \& Friston, K. J. (2010). The default-mode, ego-functions and freeenergy: A neurobiological account of Freudian ideas. Brain: A Journal of Neurology, 133(Pt 4), 1265-1283. https://doi.org/10.1093/brain/awq010

Carhart-Harris, R. L., \& Friston, K. J. (2019). REBUS and the Anarchic Brain: Toward a Unified Model of the Brain Action of Psychedelics. Pharmacological Reviews, 71(3), 316-344. https://doi.org/10.1124/pr.118.017160

Carhart-Harris, R. L., Leech, R., Hellyer, P. J., Shanahan, M., Feilding, A., Tagliazucchi, E., Chialvo, D. R., \& Nutt, D. (2014). The entropic brain: A theory of conscious states informed by neuroimaging research with psychedelic drugs. Frontiers in Human Neuroscience, 8, 20.

Carhart-Harris, R., \& Nutt, D. (2017). Serotonin and brain function: A tale of two receptors. Journal of Psychopharmacology (Oxford, England), 31(9), 1091-1120. https://doi.org/10.1177/0269881117725915 
Carson, S. (2010). Latent inhibition and creativity. In Latent inhibition: Cognition, neuroscience and applications to schizophrenia (pp. 183-198). Cambridge University Press. https://doi.org/10.1017/CBO9780511730184.010

Çatal, O., Verbelen, T., Van de Maele, T., Dhoedt, B., \& Safron, A. (2021). Robot navigation as hierarchical active inference. Neural Networks, 142, 192-204. https://doi.org/10.1016/j.neunet.2021.05.010

Chalmers, D. J. (1995). Facing Up to the Problem of Consciousness. Journal of Consciousness Studies, 2(3), 200-219.

Ciaunica, A., Charlton, J., \& Farmer, H. (2021). When the Window Cracks: Transparency and the Fractured Self in Depersonalisation. Phenomenology and the Cognitive Sciences, 20(1), 1-19. https://doi.org/10.1007/s11097-020-09677-z

Ciaunica, A., \& Safron, A. (2022). Disintegrating and Reintegrating the Self-(In)Flexible Self-Models in Depersonalisation and Psychedelic Experiences. PsyArXiv. https://doi.org/10.31234/osf.io/mah78

Crespi, B., \& Dinsdale, N. (2019). Autism and psychosis as diametrical disorders of embodiment. Evolution, Medicine, and Public Health, 2019(1), 121-138. https://doi.org/10.1093/emph/eoz021

Csíkszentmihályi, M. (1991). Flow. Harper Collins.

Darby, R. R., Joutsa, J., Burke, M. J., \& Fox, M. D. (2018). Lesion network localization of free will. Proceedings of the National Academy of Sciences of the United States of America, 115(42), 10792-10797. https://doi.org/10.1073/pnas.1814117115

Davey, C. G., \& Harrison, B. J. (2018). The brain's center of gravity: How the default mode network helps us to understand the self. World Psychiatry, 17(3), 278-279. https://doi.org/10.1002/wps.20553

Davis, A. K., Clifton, J. M., Weaver, E. G., Hurwitz, E. S., Johnson, M. W., \& Griffiths, R. R. (2020). Survey of entity encounter experiences occasioned by inhaled N,Ndimethyltryptamine: Phenomenology, interpretation, and enduring effects. Journal of Psychopharmacology, 34(9), 1008-1020. https://doi.org/10.1177/0269881120916143

De Jaegher, H. (2013). Embodiment and sense-making in autism. Frontiers in Integrative Neuroscience, 7, 15. https://doi.org/10.3389/fnint.2013.00015

de la Fuente Revenga, M., Shin, J. M., Vohra, H. Z., Hideshima, K. S., Schneck, M., Poklis, J. L., \& González-Maeso, J. (2019). Fully automated head-twitch detection system for the study of 5-HT 2A receptor pharmacology in vivo. Scientific Reports, 9(1), 14247. https://doi.org/10.1038/s41598-019-49913-4

Deane, G., Miller, M., \& Wilkinson, S. (2020). Losing Ourselves: Active Inference, Depersonalization, and Meditation. Frontiers in Psychology, 11. https://doi.org/10.3389/fpsyg.2020.539726

Deco, G., Cruzat, J., Cabral, J., Tagliazucchi, E., Laufs, H., Logothetis, N. K., \& Kringelbach, M. L. (2019). Awakening: Predicting external stimulation to force 
transitions between different brain states. Proceedings of the National Academy of Sciences, 116(36), 18088-18097. https://doi.org/10.1073/pnas.1905534116

Deco, G., \& Kringelbach, M. L. (2016). Metastability and Coherence: Extending the Communication through Coherence Hypothesis Using A Whole-Brain Computational Perspective. Trends in Neurosciences, 39(3), 125-135. https://doi.org/10.1016/j.tins.2016.01.001

Dehaene, S. (2014). Consciousness and the Brain: Deciphering How the Brain Codes Our Thoughts. Viking.

Dehaene, S., \& Changeux, J.-P. (2011). Experimental and theoretical approaches to conscious processing. Neuron, 70(2), 200-227. https://doi.org/10.1016/j.neuron.2011.03.018

Dennett, D. C. (2014). The self as the center of narrative gravity. In Self and consciousness (pp. 111-123). Psychology Press.

Dennett, D. C. (2018). Facing up to the hard question of consciousness. Philosophical Transactions of the Royal Society B: Biological Sciences, 373(1755). https://doi.org/10.1098/rstb.2017.0342

DeYoung, C. G., Flanders, J. L., \& Peterson, J. B. (2008). Cognitive Abilities Involved in Insight Problem Solving: An Individual Differences Model. Creativity Research Journal, 20(3), 278-290. https://doi.org/10.1080/10400410802278719

Dillingham, C. M., Frizzati, A., Nelson, A. J. D., \& Vann, S. D. (2015). How do mammillary body inputs contribute to anterior thalamic function? Neuroscience and Biobehavioral Reviews, 54, 108-119. https://doi.org/10.1016/j.neubiorev.2014.07.025

Dohmatob, E., Dumas, G., \& Bzdok, D. (2020). Dark control: The default mode network as a reinforcement learning agent. Human Brain Mapping, 41(12), 3318-3341. https://doi.org/10.1002/hbm.25019

Domenico, C., Haggerty, D., Mou, X., \& Ji, D. (2021). LSD degrades hippocampal spatial representations and suppresses hippocampal-visual cortical interactions. Cell Reports, 36(11). https://doi.org/10.1016/j.celrep.2021.109714

Doss, M. K., Madden, M. B., Gaddis, A., Nebel, M. B., Griffiths, R. R., Mathur, B. N., \& Barrett, F. S. (2021). Models of psychedelic drug action: Modulation of corticalsubcortical circuits. Brain: A Journal of Neurology, awab406. https://doi.org/10.1093/brain/awab406

Dujmović, M., Malhotra, G., \& Bowers, J. S. (2020). What do adversarial images tell us about human vision? ELife, 9, e55978. https://doi.org/10.7554/eLife.55978

Edelman, G. (2001). Consciousness: The Remembered Present. Annals of the New York Academy of Sciences, 929(1), 111-122. https://doi.org/10.1111/j.17496632.2001.tb05711.x

Edelman, G., \& Mountcastle, V. B. (1978). The Mindful Brain: Cortical Organization and the Group-Selective Theory of Higher Brain Function (1st ed.). MIT Press. 
Erickson, M. A., Smith, D., Albrecht, M. A., \& Silverstein, S. (2019). Alpha-band desynchronization reflects memory-specific processes during visual change detection. Psychophysiology, 56(11), e13442. https://doi.org/10.1111/psyp.13442

Erritzoe, D., Smith, J., Fisher, P. M., Carhart-Harris, R., Frokjaer, V. G., \& Knudsen, G. M. (2019). Recreational use of psychedelics is associated with elevated personality trait openness: Exploration of associations with brain serotonin markers. Journal of Psychopharmacology (Oxford, England), 269881119827891. https://doi.org/10.1177/0269881119827891

Faul, L., St. Jacques, P. L., DeRosa, J. T., Parikh, N., \& De Brigard, F. (2020). Differential contribution of anterior and posterior midline regions during mental simulation of counterfactual and perspective shifts in autobiographical memories. NeuroImage, 215, 116843. https://doi.org/10.1016/j.neuroimage.2020.116843

Freton, M., Lemogne, C., Bergouignan, L., Delaveau, P., Lehéricy, S., \& Fossati, P. (2014). The eye of the self: Precuneus volume and visual perspective during autobiographical memory retrieval. Brain Structure and Function, 219(3), 959-968. https://doi.org/10.1007/s00429-013-0546-2

Fries, P. (2015). Rhythms For Cognition: Communication Through Coherence. Neuron, 88(1), 220-235. https://doi.org/10.1016/j.neuron.2015.09.034

Friston, K., Da Costa, L., Hafner, D., Hesp, C., \& Parr, T. (2020). Sophisticated Inference. https://arxiv.org/abs/2006.04120v1

Friston, K. J. (2010). The free-energy principle: A unified brain theory? Nature Reviews. Neuroscience, 11(2), 127-138. https://doi.org/10.1038/nrn2787

Friston, K. J., Brown, H. R., Siemerkus, J., \& Stephan, K. E. (2016). The dysconnection hypothesis (2016). Schizophrenia Research, 176(2-3), 83-94. https://doi.org/10.1016/j.schres.2016.07.014

Friston, K. J., FitzGerald, T., Rigoli, F., Schwartenbeck, P., \& Pezzulo, G. (2017). Active Inference: A Process Theory. Neural Computation, 29(1), 1-49. https://doi.org/10.1162/NECO_a_00912

Friston, K. J., Kilner, J., \& Harrison, L. (2006). A free energy principle for the brain. Journal of Physiology-Paris, 100(1), 70-87. https://doi.org/10.1016/j.jphysparis.2006.10.001

Friston, K. J., Redish, A. D., \& Gordon, J. A. (2017). Computational Nosology and Precision Psychiatry. Computational Psychiatry, 1, 2-23. https://doi.org/10.1162/CPSY_a_00001

Frith, C. (2005). The neural basis of hallucinations and delusions. Comptes Rendus Biologies, 328(2), 169-175. https://doi.org/10.1016/j.crvi.2004.10.012

Gershman, S. J. (2019). The Generative Adversarial Brain. Frontiers in Artificial Intelligence, 2. https://doi.org/10.3389/frai.2019.00018 
Girn, M., Mills, C., Roseman, L., Carhart-Harris, R. L., \& Christoff, K. (2020). Updating the dynamic framework of thought: Creativity and psychedelics. NeuroImage, 213, 116726. https://doi.org/10.1016/j.neuroimage.2020.116726

Gopnik, A., O'Grady, S., Lucas, C. G., Griffiths, T. L., Wente, A., Bridgers, S., Aboody, R., Fung, H., \& Dahl, R. E. (2017). Changes in cognitive flexibility and hypothesis search across human life history from childhood to adolescence to adulthood. Proceedings of the National Academy of Sciences, 114(30), 7892-7899. https://doi.org/10.1073/pnas.1700811114

Gothoskar, N., Guntupalli, J. S., Rikhye, R. V., Lázaro-Gredilla, M., \& George, D. (2019). Different clones for different contexts: Hippocampal cognitive maps as higherorder graphs of a cloned HMM. BioRxiv, 745950. https://doi.org/10.1101/745950

Graziano, M. S. A. (2013). Consciousness and the Social Brain. Oxford University Press.

Graziano, M. S. A. (2019). Rethinking consciousness: A scientific theory of subjective experience (First Edition.). WWNorton \& Company.

Griffiths, R. R., Johnson, M. W., Carducci, M. A., Umbricht, A., Richards, W. A., Richards, B. D., Cosimano, M. P., \& Klinedinst, M. A. (2016). Psilocybin produces substantial and sustained decreases in depression and anxiety in patients with life-threatening cancer: A randomized double-blind trial. Journal of Psychopharmacology (Oxford, England), 30(12), 1181-1197.

https://doi.org/10.1177/0269881116675513

Grof, S. (1977). Perinatal Roots of Wars, Totalitarianism, and Revolutions: Observations from LSD Research. The Journal of Psychohistory, 4(3), 269-308.

Gupta, T., Silverstein, S. M., Bernard, J. A., Keane, B. P., Papathomas, T. V., PelletierBaldelli, A., Dean, D. J., Newberry, R. E., Ristanovic, I., \& Mittal, V. A. (2016). Disruptions in neural connectivity associated with reduced susceptibility to a depth inversion illusion in youth at ultra high risk for psychosis. NeuroImage: Clinical, 12, 681-690. https://doi.org/10.1016/j.nicl.2016.09.022

Halberstadt, A. L., Chatha, M., Klein, A. K., Wallach, J., \& Brandt, S. D. (2020). Correlation between the potency of hallucinogens in the mouse head-twitch response assay and their behavioral and subjective effects in other species. Neuropharmacology, 167, 107933. https://doi.org/10.1016/j.neuropharm.2019.107933 Hassabis, D., \& Maguire, E. A. (2009). The construction system of the brain. Philosophical Transactions of the Royal Society of London. Series B, Biological Sciences, 364(1521), 1263-1271. https://doi.org/10.1098/rstb.2008.0296

Hassabis, D., Spreng, R. N., Rusu, A. A., Robbins, C. A., Mar, R. A., \& Schacter, D. L. (2014). Imagine All the People: How the Brain Creates and Uses Personality Models to Predict Behavior. Cerebral Cortex, 24(8), 1979-1987. https://doi.org/10.1093/cercor/bht042

Hawkins, J. (2021). A Thousand Brains: A New Theory of Intelligence. Basic Books. Hawkins, J., \& Blakeslee, S. (2004). On Intelligence (Adapted). Times Books. 
Hayes, S. C. (2019). A Liberated Mind: How to Pivot Toward What Matters. Penguin.

Hazlett, E. A., New, A. S., Newmark, R., Haznedar, M. M., Lo, J. N., Speiser, L. J., Chen, A. D., Mitropoulou, V., Minzenberg, M., Siever, L. J., \& Buchsbaum, M. S. (2005). Reduced anterior and posterior cingulate gray matter in borderline personality disorder. Biological Psychiatry, 58(8), 614-623. https://doi.org/10.1016/j.biopsych.2005.04.029

Hesp, C., Tschantz, A., Millidge, B., Ramstead, M., Friston, K., \& Smith, R. (2020). Sophisticated Affective Inference: Simulating Anticipatory Affective Dynamics of Imagining Future Events. In T. Verbelen, P. Lanillos, C. L. Buckley, \& C. De Boom (Eds.), Active Inference (pp. 179-186). Springer International Publishing. https://doi.org/10.1007/978-3-030-64919-7_18

Hills, T. T., Todd, P. M., \& Goldstone, R. L. (2010). The Central Executive as a Search Process: Priming Exploration and Exploitation across Domains. Journal of Experimental Psychology. General, 139(4), 590-609. https://doi.org/10.1037/a0020666

Hinton, D. E., \& Kirmayer, L. J. (2017). The Flexibility Hypothesis of Healing. Culture, Medicine and Psychiatry, 41(1), 3-34. https://doi.org/10.1007/s11013-016-9493-8

Hutter, M. (2000). A Theory of Universal Artificial Intelligence based on Algorithmic Complexity. ArXiv:Cs/0004001. http://arxiv.org/abs/cs/0004001

Jacob, G., Pramod, R. T., Katti, H., \& Arun, S. P. (2021). Qualitative similarities and differences in visual object representations between brains and deep networks. Nature Communications, 12(1), Article 1. https://doi.org/10.1038/s41467-021-220783

James, W. (1890). The Principles of Psychology, Vol. 1 (Reprint edition). Dover Publications.

James, W. (1902). The Varieties of Religious Experience: A Study in Human Nature. Modern library.

Jann, K., Dierks, T., Boesch, C., Kottlow, M., Strik, W., \& Koenig, T. (2009). BOLD correlates of EEG alpha phase-locking and the fMRI default mode network. NeuroImage, 45(3), 903-916.

Jansen, K. L. R. (1997). The Ketamine Model of the Near-Death Experience: A Central Role for the N-Methyl-D-Aspartate Receptor. Journal of Near-Death Studies, 16(1), 5-26. https://doi.org/10.1023/A:1025055109480

Ji, X., Elmoznino, E., Deane, G., Constant, A., Dumas, G., Lajoie, G., Simon, J., \& Bengio, Y. (2023). Sources of Richness and Ineffability for Phenomenally Conscious States (arXiv:2302.06403). arXiv. https://doi.org/10.48550/arXiv.2302.06403

Johnson, M., Richards, W., \& Griffiths, R. (2008). Human hallucinogen research: Guidelines for safety. Journal of Psychopharmacology (Oxford, England), 22(6), 603620. https://doi.org/10.1177/0269881108093587 
Johnson, M. W. (2021). Consciousness, Religion, and Gurus: Pitfalls of Psychedelic Medicine. ACS Pharmacology \& Translational Science, 4(2), 578-581.

https://doi.org/10.1021/acsptsci.0c00198

Johnson, M. W., Hendricks, P. S., Barrett, F. S., \& Griffiths, R. R. (2019). Classic psychedelics: An integrative review of epidemiology, therapeutics, mystical experience, and brain network function. Pharmacology \& Therapeutics, 197, 83-102. https://doi.org/10.1016/j.pharmthera.2018.11.010

Kaplan, R., \& Friston, K. J. (2018). Planning and navigation as active inference. Biological Cybernetics, 112(4), 323-343. https://doi.org/10.1007/s00422-018-0753-2

Kay, K., Chung, J. E., Sosa, M., Schor, J. S., Karlsson, M. P., Larkin, M. C., Liu, D. F., \& Frank, L. M. (2020). Constant Sub-second Cycling between Representations of Possible Futures in the Hippocampus. Cell, 180(3), 552-567.e25. https://doi.org/10.1016/j.cell.2020.01.014

Kenett, Y. N., Medaglia, J. D., Beaty, R. E., Chen, Q., Betzel, R. F., Thompson-Schill, S. L., \& Qiu, J. (2018a). Driving the brain towards creativity and intelligence: A network control theory analysis. Neuropsychologia, 118(Pt A), 79-90. https://doi.org/10.1016/j.neuropsychologia.2018.01.001

Kenett, Y. N., Medaglia, J. D., Beaty, R. E., Chen, Q., Betzel, R. F., Thompson-Schill, S. L., \& Qiu, J. (2018b). Driving the brain towards creativity and intelligence: A network control theory analysis. Neuropsychologia, 118, 79-90. https://doi.org/10.1016/j.neuropsychologia.2018.01.001

Kerr, C. E., Sacchet, M. D., Lazar, S. W., Moore, C. I., \& Jones, S. R. (2013). Mindfulness starts with the body: Somatosensory attention and top-down modulation of cortical alpha rhythms in mindfulness meditation. Frontiers in Human Neuroscience, 7, 12. https://doi.org/10.3389/fnhum.2013.00012

Knyazev, G. G., Slobodskoj-Plusnin, J. Y., Bocharov, A. V., \& Pylkova, L. V. (2011). The default mode network and EEG alpha oscillations: An independent component analysis. Brain Research, 1402, 67-79. https://doi.org/10.1016/j.brainres.2011.05.052

Koster, R., Chadwick, M. J., Chen, Y., Berron, D., Banino, A., Düzel, E., Hassabis, D., \& Kumaran, D. (2018). Big-Loop Recurrence within the Hippocampal System Supports Integration of Information across Episodes. Neuron, 99(6), 1342-1354.e6. https://doi.org/10.1016/j.neuron.2018.08.009

Krupitsky, E. M., \& Grinenko, A. Y. (1997). Ketamine psychedelic therapy (KPT): A review of the results of ten years of research. Journal of Psychoactive Drugs, 29(2), 165-183. https://doi.org/10.1080/02791072.1997.10400185

Lau, H., Michel, M., LeDoux, J. E., \& Fleming, S. M. (2022). The mnemonic basis of subjective experience. Nature Reviews Psychology, 1(8), Article 8. https://doi.org/10.1038/s44159-022-00068-6

Lawson, R. P., Rees, G., \& Friston, K. J. (2014). An aberrant precision account of autism. Frontiers in Human Neuroscience, 8. https://doi.org/10.3389/fnhum.2014.00302 
Leech, R., \& Sharp, D. J. (2014). The role of the posterior cingulate cortex in cognition and disease. Brain, 137(1), 12-32. https://doi.org/10.1093/brain/awt162

Li, M., Woelfer, M., Colic, L., Safron, A., Chang, C., Heinze, H.-J., Speck, O., Mayberg, H. S., Biswal, B. B., Salvadore, G., Fejtova, A., \& Walter, M. (2018). Default mode network connectivity change corresponds to ketamine's delayed glutamatergic effects. European Archives of Psychiatry and Clinical Neuroscience. https://doi.org/10.1007/s00406-018-0942-y

MacLean, K. A., Johnson, M. W., \& Griffiths, R. R. (2011). Mystical Experiences Occasioned by the Hallucinogen Psilocybin Lead to Increases in the Personality Domain of Openness. Journal of Psychopharmacology (Oxford, England), 25(11), 1453-1461. https://doi.org/10.1177/0269881111420188

Markram, K., \& Markram, H. (2010). The intense world theory - A unifying theory of the neurobiology of autism. Frontiers in Human Neuroscience, 4, 224. https://doi.org/10.3389/fnhum.2010.00224

Marr, D. (1983). Vision: A Computational Investigation into the Human Representation and Processing of Visual Information. Henry Holt and Company.

Martial, C., Cassol, H., Charland-Verville, V., Pallavicini, C., Sanz, C., Zamberlan, F., Vivot, R. M., Erowid, F., Erowid, E., Laureys, S., Greyson, B., \& Tagliazucchi, E. (2019). Neurochemical models of near-death experiences: A large-scale study based on the semantic similarity of written reports. Consciousness and Cognition, 69, 52-69. https://doi.org/10.1016/j.concog.2019.01.011

Martial, C., Fontaine, G., Gosseries, O., Carhart-Harris, R., Timmermann, C., Laureys, S., \& Cassol, H. (2021). Losing the Self in Near-Death Experiences: The Experience of Ego-Dissolution. Brain Sciences, 11(7), Article 7.

https://doi.org/10.3390/brainsci11070929

McNamee, D. C., Stachenfeld, K. L., Botvinick, M. M., \& Gershman, S. J. (2021). Flexible modulation of sequence generation in the entorhinal-hippocampal system. Nature Neuroscience, 24(6), Article 6. https://doi.org/10.1038/s41593-021-00831-7

Mediano, P. A. M., Rosas, F. E., Timmermann, C., Roseman, L., Nutt, D. J., Feilding, A., Kaelen, M., Kringelbach, M. L., Barrett, A. B., Seth, A. K., Muthukumaraswamy, S., Bor, D., \& Carhart-Harris, R. L. (2020). Effects of external stimulation on psychedelic state neurodynamics. BioRxiv, 2020.11.01.356071. https://doi.org/10.1101/2020.11.01.356071

Metzinger, T. (2010). The Ego Tunnel: The Science of the Mind and the Myth of the Self. ReadHowYouWant.com.

Michaiel, A. M., Parker, P. R. L., \& Niell, C. M. (2019). A Hallucinogenic Serotonin-2A Receptor Agonist Reduces Visual Response Gain and Alters Temporal Dynamics in Mouse V1. Cell Reports, 26(13), 3475-3483.e4.

https://doi.org/10.1016/j.celrep.2019.02.104 
Michalareas, G., Vezoli, J., van Pelt, S., Schoffelen, J.-M., Kennedy, H., \& Fries, P. (2016). Alpha-beta and gamma rhythms subserve feedback and feedforward influences among human visual cortical areas. Neuron, 89(2), 384-397. https://doi.org/10.1016/j.neuron.2015.12.018

Mountcastle, V. B. (1997). The columnar organization of the neocortex. Brain: A Journal of Neurology, 120 ( Pt 4), 701-722.

Moutkine, I., Collins, E. L., Béchade, C., \& Maroteaux, L. (2019). Evolutionary considerations on 5-HT2 receptors. Pharmacological Research, 140, 14-20. https://doi.org/10.1016/j.phrs.2018.09.014

Nagel, T. (1974). What Is It Like to Be a Bat? The Philosophical Review, 83(4), 435-450. JSTOR. https://doi.org/10.2307/2183914

Noel, J.-P., Cascio, C. J., Wallace, M. T., \& Park, S. (2017). The Spatial Self in Schizophrenia and Autism Spectrum Disorder. Schizophrenia Research, 179, 8-12. https://doi.org/10.1016/j.schres.2016.09.021

O'Callaghan, C., Walpola, I. C., \& Shine, J. M. (2021). Neuromodulation of the mindwandering brain state: The interaction between neuromodulatory tone, sharp wave-ripples and spontaneous thought. Philosophical Transactions of the Royal Society of London. Series B, Biological Sciences, 376(1817), 20190699. https://doi.org/10.1098/rstb.2019.0699

O'Reilly, R. C., Wyatte, D. R., \& Rohrlich, J. (2017). Deep Predictive Learning: A Comprehensive Model of Three Visual Streams. ArXiv:1709.04654 [q-Bio]. http://arxiv.org/abs/1709.04654

Ott, U., Reuter, M., Hennig, J., \& Vaitl, D. (2005). Evidence for a common biological basis of the Absorption trait, hallucinogen effects, and positive symptoms: Epistasis between 5-HT2a and COMT polymorphisms. American Journal of Medical Genetics. Part B, Neuropsychiatric Genetics: The Official Publication of the International Society of Psychiatric Genetics, 137B(1), 29-32. https://doi.org/10.1002/ajmg.b.30197

Palacios, E. R., Isomura, T., Parr, T., \& Friston, K. J. (2019). The emergence of synchrony in networks of mutually inferring neurons. Scientific Reports, 9(1), 6412. https://doi.org/10.1038/s41598-019-42821-7

Palva, S., \& Palva, J. M. (2011). Functional Roles of Alpha-Band Phase Synchronization in Local and Large-Scale Cortical Networks. Frontiers in Psychology, 2. https://doi.org/10.3389/fpsyg.2011.00204

Papez, J.W. (1937). A proposed mechanism of emotion. Archives of Neurology $\mathcal{E}$ Psychiatry, 38(4), 725-743. https://doi.org/10.1001/archneurpsyc.1937.02260220069003

Parr, T., \& Friston, K. J. (2017). Working memory, attention, and salience in active inference. Scientific Reports, 7(1), 14678. https://doi.org/10.1038/s41598-017-152490 
Penn, D. C., Holyoak, K. J., \& Povinelli, D. J. (2008). Darwin's mistake: Explaining the discontinuity between human and nonhuman minds. The Behavioral and Brain Sciences, 31(2), 109-130; discussion 130-178. https://doi.org/10.1017/S0140525X08003543

Pink-Hashkes, S., Rooij, I. J. E. I. van, \& Kwisthout, J. (2017). Perception is in the Details: A Predictive Coding Account of the Psychedelic Phenomenon. CogSci.

Pollan, M. (2018). How to Change Your Mind: The New Science of Psychedelics. Penguin Books Limited.

Pollan, M. (2021). This Is Your Mind on Plants. Penguin.

Preller, K. H., Razi, A., Zeidman, P., Stämpfli, P., Friston, K. J., \& Vollenweider, F. X. (2019). Effective connectivity changes in LSD-induced altered states of consciousness in humans. Proceedings of the National Academy of Sciences of the United States of America, 116(7), 2743-2748. https://doi.org/10.1073/pnas.1815129116

Prinz, J. (2017). The Intermediate Level Theory of Consciousness. In The Blackwell Companion to Consciousness (pp. 257-271). John Wiley \& Sons, Ltd. https://doi.org/10.1002/9781119132363.ch18

Pyszczynski, T., Solomon, S., \& Greenberg, J. (2015). Chapter One - Thirty Years of Terror Management Theory: From Genesis to Revelation. In J. M. Olson \& M. P. Zanna (Eds.), Advances in Experimental Social Psychology (Vol. 52, pp. 1-70). Academic Press. https://doi.org/10.1016/bs.aesp.2015.03.001

Rabinowitz, N. C., Perbet, F., Song, H. F., Zhang, C., Eslami, S. M. A., \& Botvinick, M. (2018). Machine Theory of Mind. ArXiv:1802.07740 [Cs]. http://arxiv.org/abs/1802.07740

Rudrauf, D., Lutz, A., Cosmelli, D., Lachaux, J.-P., \& Le Van Quyen, M. (2003). From autopoiesis to neurophenomenology: Francisco Varela's exploration of the biophysics of being. Biological Research, 36(1), 27-65.

Rueter, A. R., Abram, S. V., MacDonald, A. W., Rustichini, A., \& DeYoung, C. G. (2018). The goal priority network as a neural substrate of Conscientiousness. Human Brain Mapping, 39(9), 3574-3585. https://doi.org/10.1002/hbm.24195

Sacks, O. (2013). Hallucinations (1st edition). Vintage.

Safron, A. (2016). What is orgasm? A model of sexual trance and climax via rhythmic entrainment. Socioaffective Neuroscience \& Psychology, 6, 31763.

Safron, A. (2020a). An Integrated World Modeling Theory (IWMT) of Consciousness: Combining Integrated Information and Global Neuronal Workspace Theories With the Free Energy Principle and Active Inference Framework; Toward Solving the Hard Problem and Characterizing Agentic Causation. Frontiers in Artificial Intelligence, 3. https://doi.org/10.3389/frai.2020.00030 
Safron, A. (2020b). Integrated World Modeling Theory (IWMT) Implemented: Towards Reverse Engineering Consciousness with the Free Energy Principle and Active Inference. PsyArXiv. https://doi.org/10.31234/osf.io/paz5j

Safron, A. (2021a). The Radically Embodied Conscious Cybernetic Bayesian Brain: From Free Energy to Free Will and Back Again. Entropy, 23(6), Article 6. https://doi.org/10.3390/e23060783

Safron, A. (2021b). Integrated World Modeling Theory (IWMT) Expanded: Implications for Theories of Consciousness and Artificial Intelligence. PsyArXiv. https://doi.org/10.31234/osf.io/rm5b2

Safron, A., Çatal, O., \& Verbelen, T. (2021). Generalized Simultaneous Localization and Mapping (G-SLAM) as unification framework for natural and artificial intelligences: Towards reverse engineering the hippocampal/entorhinal system and principles of highlevel cognition. PsyArXiv. https://doi.org/10.31234/osf.io/tdw82

Safron, A., \& DeYoung, C. G. (2021). Chapter 18 - Integrating Cybernetic Big Five Theory with the free energy principle: A new strategy for modeling personalities as complex systems. In D. Wood, S. J. Read, P. D. Harms, \& A. Slaughter (Eds.), Measuring and Modeling Persons and Situations (pp. 617-649). Academic Press. https://doi.org/10.1016/B978-0-12-819200-9.00010-7

Safron, A., Klimaj, V., \& Hipólito, I. (2021). On the importance of being flexible: Dynamic brain networks and their potential functional significances. PsyArXiv. https://doi.org/10.31234/osf.io/x734w

Safron, A., Sakthivadivel, D. A. R., Sheikhbahaee, Z., Bein, M., Razi, A., \& Levin, M. (2023). Making and breaking symmetries in mind and life. Interface Focus, 13(3), 20230015. https://doi.org/10.1098/rsfs.2023.0015

Safron, A., \& Sheikhbahaee, Z. (2021). Dream to explore: 5-HT2a as adaptive temperature parameter for sophisticated affective inference. PsyArXiv. https://doi.org/10.31234/osf.io/zmpaq

Sandved Smith, L., Hesp, C., Lutz, A., Mattout, J., Friston, K., \& Ramstead, M. (2020). Towards a formal neurophenomenology of metacognition: Modelling meta-awareness, mental action, and attentional control with deep active inference [Preprint]. PsyArXiv. https://doi.org/10.31234/osf.io/5jh3c

Sato, J., Mossad, S. I., Wong, S. M., Hunt, B. A. E., Dunkley, B. T., Smith, M. L., Urbain, C., \& Taylor, M. J. (2018). Alpha keeps it together: Alpha oscillatory synchrony underlies working memory maintenance in young children. Developmental Cognitive Neuroscience, 34, 114-123. https://doi.org/10.1016/j.dcn.2018.09.001

Schmidhuber, J. (2002). Hierarchies of generalized kolmogorov complexities and nonenumerable universal measures computable in the limit. International Journal of Foundations of Computer Science, 13(04), 587-612. https://doi.org/10.1142/S0129054102001291 
Schmidt, C. J., Sorensen, S. M., Kehne, J. H., Carr, A. A., \& Palfreyman, M. G. (1995). The role of 5-HT2A receptors in antipsychotic activity. Life Sciences, 56(25), 2209-2222. https://doi.org/10.1016/0024-3205(95)00210-w

Seth, A. (2021). Being You: A New Science of Consciousness. Dutton.

Seth, A. K. (2016, November 2). The hard problem of consciousness is a distraction from the real one - Anil K Seth I Aeon Essays. Aeon. https://aeon.co/essays/the-hardproblem-of-consciousness-is-a-distraction-from-the-real-one

Seth, A. K., \& Tsakiris, M. (2018). Being a Beast Machine: The Somatic Basis of Selfhood. Trends in Cognitive Sciences, 22(11), 969-981. https://doi.org/10.1016/j.tics.2018.08.008

Sharp, P. E., \& Koester, K. (2008). Lesions of the mammillary body region severely disrupt the cortical head direction, but not place cell signal. Hippocampus, 18(8), 766-784. https://doi.org/10.1002/hipo.20436

Smigielski, L., Scheidegger, M., Kometer, M., \& Vollenweider, F. X. (2019). Psilocybinassisted mindfulness training modulates self-consciousness and brain default mode network connectivity with lasting effects. Neurolmage, 196, 207-215. https://doi.org/10.1016/j.neuroimage.2019.04.009

Snider, R. S., \& Maiti, A. (1976). Cerebellar contributions to the Papez circuit. Journal of Neuroscience Research, 2(2), 133-146. https://doi.org/10.1002/jnr.490020204

Sormaz, M., Murphy, C., Wang, H., Hymers, M., Karapanagiotidis, T., Poerio, G., Margulies, D. S., Jefferies, E., \& Smallwood, J. (2018). Default mode network can support the level of detail in experience during active task states. Proceedings of the National Academy of Sciences, 115(37), 9318-9323. https://doi.org/10.1073/pnas.1721259115

Sreekumar, V., Nielson, D. M., Smith, T. A., Dennis, S. J., \& Sederberg, P. B. (2018). The experience of vivid autobiographical reminiscence is supported by subjective content representations in the precuneus. Scientific Reports, 8(1), 14899. https://doi.org/10.1038/s41598-018-32879-0

Stachenfeld, K. L., Botvinick, M. M., \& Gershman, S. J. (2017). The hippocampus as a predictive map. Nature Neuroscience, 20(11), Article 11. https://doi.org/10.1038/nn.4650

Stanley, K. O., \& Lehman, J. (2015). Why Greatness Cannot Be Planned: The Myth of the Objective. Springer.

Strogatz, S. H. (1994). Norbert Wiener's Brain Waves. In S. A. Levin (Ed.), Frontiers in Mathematical Biology (pp. 122-138). Springer Berlin Heidelberg.

Suzuki, K., Roseboom, W., Schwartzman, D. J., \& Seth, A. K. (2017). A Deep-Dream Virtual Reality Platform for Studying Altered Perceptual Phenomenology. Scientific Reports, 7(1), Article 1. https://doi.org/10.1038/s41598-017-16316-2 
Szegedy, C., Liu, W., Jia, Y., Sermanet, P., Reed, S., Anguelov, D., Erhan, D., Vanhoucke, V., \& Rabinovich, A. (2014). Going Deeper with Convolutions. ArXiv:1409.4842 [Cs]. http://arxiv.org/abs/1409.4842

Tellegen, A. (1982). Content categories: Absorption Items (Revised). Unpublished manuscript, University of Minnesota.

Tononi, G., Boly, M., Massimini, M., \& Koch, C. (2016). Integrated information theory: From consciousness to its physical substrate. Nature Reviews Neuroscience, 17(7), 450. https://doi.org/10.1038/nrn.2016.44

Turi, M., Burr, D. C., \& Binda, P. (2018). Pupillometry reveals perceptual differences that are tightly linked to autistic traits in typical adults. ELife, 7, e32399. https://doi.org/10.7554/eLife.32399

ul Haq, R., Anderson, M. L., Hollnagel, J.-O., Worschech, F., Sherkheli, M. A., Behrens, C. J., \& Heinemann, U. (2016). Serotonin dependent masking of hippocampal sharp wave ripples. Neuropharmacology, 101, 188-203. https://doi.org/10.1016/j.neuropharm.2015.09.026

Varela, F. J. (1999). Present-Time Consciousness. Journal of Consciousness Studies, 6(2-3), 111-140.

Varela, F. J., Thompson, E. T., \& Rosch, E. (1992). The Embodied Mind: Cognitive Science and Human Experience (Revised ed. edition). The MIT Press.

Walsh, K. S., McGovern, D. P., Clark, A., \& O'Connell, R. G. (2020). Evaluating the neurophysiological evidence for predictive processing as a model of perception. Annals of the New York Academy of Sciences, 1464(1), 242-268. https://doi.org/10.1111/nyas.14321

Wengler, K., Goldberg, A. T., Chahine, G., \& Horga, G. (2020). Distinct hierarchical alterations of intrinsic neural timescales account for different manifestations of psychosis. ELife, 9, e56151. https://doi.org/10.7554/eLife.56151

Whittington, J. C., Muller, T. H., Mark, S., Chen, G., Barry, C., Burgess, N., \& Behrens, T. E. (2019). The Tolman-Eichenbaum Machine: Unifying space and relational memory through generalisation in the hippocampal formation. BioRxiv, 770495. https://doi.org/10.1101/770495

Widloski, J., \& Foster, D. J. (2022). Flexible rerouting of hippocampal replay sequences around changing barriers in the absence of global place field remapping. Neuron. https://doi.org/10.1016/j.neuron.2022.02.002

Wiese, W. (2020). The science of consciousness does not need another theory, it needs a minimal unifying model. Neuroscience of Consciousness, 2020(niaa013). https://doi.org/10.1093/nc/niaa013

Wijesinghe, R., Protti, D. A., \& Camp, A. J. (2015). Vestibular Interactions in the Thalamus. Frontiers in Neural Circuits, 9. https://doi.org/10.3389/fncir.2015.00079

Willins, D. L., Deutch, A. Y., \& Roth, B. L. (1997). Serotonin 5-HT2A receptors are expressed on pyramidal cells and interneurons in the rat cortex. Synapse, 27(1), 
79-82. https://doi.org/10.1002/(SICI)1098-2396(199709)27:1<79::AID-

SYN8>3.0.CO;2-A

Xie, S., Kaiser, D., \& Cichy, R. M. (2020). Visual Imagery and Perception Share Neural Representations in the Alpha Frequency Band. Current Biology, 30(13), 26212627.e5. https://doi.org/10.1016/j.cub.2020.04.074

Yaden, D. B., Johnson, M. W., Griffiths, R. R., Doss, M. K., Garcia-Romeu, A., Nayak, S., Gukasyan, N., Mathur, B. N., \& Barrett, F. S. (2021). Psychedelics and Consciousness: Distinctions, Demarcations, and Opportunities. International Journal of Neuropsychopharmacology, pyab026. https://doi.org/10.1093/ijnp/pyab026

Zhou, Y., Friston, K. J., Zeidman, P., Chen, J., Li, S., \& Razi, A. (2018). The Hierarchical Organization of the Default, Dorsal Attention and Salience Networks in Adolescents and Young Adults. Cerebral Cortex (New York, NY), 28(2), 726-737. https://doi.org/10.1093/cercor/bhx307 